OPEN ACCESS

Edited by:

David Baglietto-Vargas,

University of California, Irvine,

United States

Reviewed by:

Gerald Seifert,

University Hospital Bonn, Germany

Ryo Yamasaki,

Kyushu University, Japan

Katsuhisa Masaki,

University of Chicago Medical Center

United States

*Correspondence: Kleopas A. Kleopa kleopa@cing.ac.cy

Specialty section:

This article was submitted to

Neurodegeneration,

a section of the journal

Frontiers in Neuroscience

Received: 13 July 2020

Accepted: 14 September 2020

Published: 07 October 2020

Citation:

Angeli S, Kousiappa I, Stavrou M,

Sargiannidou I, Georgiou E,

Papacostas SS and Kleopa KA (2020)

Altered Expression of Glial Gap

Junction Proteins $C \times 43, C \times 30$,

and $\mathrm{CX} 47$ in the 5XFAD Model

of Alzheimer's Disease.

Front. Neurosci. 14:582934.

doi: 10.3389/fnins.2020.582934

\section{Altered Expression of Glial Gap Junction Proteins Cx43, Cx30, and Cx47 in the 5XFAD Model of Alzheimer's Disease}

\author{
Stella Angeli ${ }^{1,2}$, Ioanna Kousiappa ${ }^{1,2}$, Marios Stavrou $^{3}$, Irene Sargiannidou ${ }^{2,4}$, \\ Elena Georgiou ${ }^{2,4}$, Savvas S. Papacostas ${ }^{1,2,5,6}$ and Kleopas A. Kleopa ${ }^{2,4,7,8 *}$ \\ ${ }^{1}$ Neurobiology Department, The Cyprus Institute of Neurology and Genetics, Nicosia, Cyprus, ${ }^{2}$ Cyprus School of Molecular \\ Medicine, Nicosia, Cyprus, ${ }^{3}$ Department of Electrical and Computer Engineering, Faculty of Engineering, University of \\ Cyprus, Nicosia, Cyprus, ${ }^{4}$ Neuroscience Department, The Cyprus Institute of Neurology and Genetics, Nicosia, Cyprus, \\ ${ }^{5}$ Dementia and Cognitive Disorders Center, The Cyprus Institute of Neurology and Genetics, Nicosia, Cyprus, ${ }^{6}$ Medical \\ School, University of Nicosia, Nicosia, Cyprus, ${ }^{7}$ Center for Neuromuscular disorders, The Cyprus Institute of Neurology and \\ Genetics, Nicosia, Cyprus, ${ }^{8}$ Center for Multiple Sclerosis and Related Disorders, The Cyprus Institute of Neurology and \\ Genetics, Nicosia, Cyprus
}

Glial gap junction proteins, called connexins (Cxs), form gap junctions in the central nervous system (CNS) to allow the bidirectional cytosolic exchange of molecules between adjacent cells. Their involvement in inheritable diseases and the use of experimental animal models that closely mimic such diseases revealed the critical role of glial GJs in myelination and homeostasis. Cxs are also implicated in acquired demyelinating disorders, such as Multiple Sclerosis (MS) and Alzheimer's disease (AD). Animal and human studies have revealed a role of the astrocytic $\mathrm{C} \times 43$ in the progression of $A D$ but the role of $\mathrm{Cx} 47$, which is the main partner of $\mathrm{C} \times 43$ in the astrocyteoligodendrocyte GJs is still unknown. The aim of this study was to investigate the astrocytic connexins, Cx43 and Cx30 in relation to oligodendrocytic Cx47 in the cortex and thalamus of the 5XFAD mouse model of AD. The model was characterized by increased $A \beta$ deposition, gliosis, neuronal loss, and memory impairment. Compared to wild-type mice, CX43 and Cx30 showed increased immunoreactivity in older 5XFAD mice, reflecting astrogliosis, while Cx47 immunoreactivity was reduced. Moreover, Cx47 GJ plaques showed reduced colocalization with Cx43 plaques. Oligodendrocyte precursor cells (OPCs) and mature oligodendrocyte populations were also depleted, and myelin deficits were observed. Our findings indicate reduced astrocyte-oligodendrocyte gap junction connectivity and possibly a shift in Cx43 expression toward astrocyteastrocyte gap junctions and/or hemichannels, that could impair oligodendrocyte homeostasis and myelination. However, other factors, such as A $\beta$ toxicity, could directly affect oligodendrocyte survival in AD. Our study provides evidence that $\mathrm{Cxs}$ might have implications in the progression of $A D$, although the role of oligodendrocyte $C x s$ in $A D$ requires further investigation. 


\section{INTRODUCTION}

Alzheimer's disease (AD) is the most common form of irreversible dementia and is characterized by the loss of cognitive function (Skaper, 2012). The hallmarks of AD include extracellular plaques formed by aggregated amyloid- $\beta$ (A $\beta$ ) peptides and intracellular neurofibrillary tangles (aggregates of hyperphosphorylated tau protein). Familial AD mutations in the $A P P$ and PSEN1 genes affect the proteolytic processing of the amyloid precursor protein (APP), with increased accumulation of $A \beta$ peptides (especially $A \beta_{42}$ ) causing neuronal toxicity (Hardy and Selkoe, 2002; Haass and Selkoe, 2007; Reiss et al., 2018). Tissue damage caused by $A \beta$ accumulation was confirmed in 5XFAD mice, a transgenic mouse model of familial AD, by showing elevated levels of nitrotyrosine (NT), a toxic product of superoxide reaction with nitric oxide (NO) (Modi et al., 2015). Also, in AD, the inducible NO synthase (iNOS), which is produced by astrocytes, microglia and macrophages (Nathan et al., 2005) generates increased levels of NO which causes oxidative stress, consequently leading to neurodegeneration (Balez and Ooi, 2016). However, INOS gene expression levels in 5XFAD and control mice were found to be similar, indicating that iNOS is not excessively produced by glial cells of this mouse model (Griñán-Ferré et al., 2016).

In neurodegenerative diseases, like $\mathrm{AD}$, glial cells, including astrocytes, microglia, and oligodendrocytes, activate and trigger hazardous neuroinflammatory reactions inducing neuronal death (Cragnolini et al., 2020). Glial cells are part of an organized network that offers communication and support via gap junctions (GJs) (Giaume et al., 2010). Adjacent glial cells form GJs which are composed of opposing hexamers of connexins (Cxs) (Yamasaki, 2018), which are involved in the exchange of small molecules and ions such as $\mathrm{Ca}^{2+}$, cAMP, ATP and glutamate and contribute to long distance intercellular signaling (Takeuchi and Suzumura, 2014). In the central nervous system (CNS), the astroglial-astroglial (A/A), and astroglial-oligodendroglial $(\mathrm{A} / \mathrm{O})$ coupling plays a major role in the maintenance of myelination, neuronal homeostasis, and synaptic neurotransmission (Yamasaki, 2018). Astrocytic Cx43 only couples with itself in the A/A GJs and with $\mathrm{Cx} 47$ in the $\mathrm{A} / \mathrm{O}$ GJs, whereas astrocytic $\mathrm{Cx} 30$ couples with itself in the A/A GJs and with Cx32 in the A/O GJs (Nagy et al., 2003; Kleopa et al., 2004; Orthmann-Murphy et al., 2007).

Cxs are known to be implicated in disease either by mutations in $\mathrm{Cx}$ genes that cause inheritable diseases or by primary or secondary $\mathrm{Cx}$ dysfunctions that cause acquired disorders (Yamasaki, 2018). GJB1 (Cx32) gene mutations cause the X-linked Charcot-Marie-Tooth disease, a disease of the peripheral nervous system, where Schwann cells fail to provide metabolic or trophic support for the physiological function of axons (Jeng et al., 2006). Autosomal recessive GJC2 (Cx47) gene mutations cause the Pelizaeus Merzbacher-like disease, a hypomyelinating leukodystrophy (Uhlenberg et al., 2004). Also, oculodentodigital dysplasia is an autosomal dominant syndrome caused by GJA1 (Cx43) gene mutations characterized by CNS demyelination and progressive spastic paraplegia (Paznekas et al., 2003), highlighting the importance of astrocytic coupling with oligodendrocytes, the myelinating cells of the CNS, for the homeostasis and survival of the latter. The crucial role of GJs for CNS myelination is validated in mouse models of these disorders (Sutor et al., 2000; Odermatt et al., 2003; Lutz et al., 2009; Sargiannidou et al., 2009; Magnotti et al., 2011; Tress et al., 2012). In addition, in mutant Superoxide dismutase- 1 transgenic mice (mouse model of motor neuron disease), neuronal Cx36, which is responsible for the development of electrical synapses (Bautista et al., 2014), showed reduced expression (Belousov et al., 2018; Kobayakawa et al., 2018). In addition, the upregulation of $C x$ hemichannels (HCs) is linked to the activation of microglia and astrocytes in these mice (Cui et al., 2014). Cxs are also implicated in Multiple Sclerosis (MS) and the experimental autoimmune encephalomyelitis (EAE) mouse model of MS (Brand-Schieber et al., 2005; Eugenin et al., 2012; Markoullis et al., 2012a,b, 2014). In both MS and EAE, Cx32 was reduced within and around lesions, in acute and chronic stages, particularly in areas with severe inflammation (Markoullis et al., 2012a,b). In acute EAE, Cx47 was not reduced but rather redistributed from GJ plaques intracellularly, while in chronic EAE, Cx47 GJs were lost. However, Cx43 GJ plaques were disrupted in acute MS (Masaki, 2013) and EAE lesions (Markoullis et al., 2012a) but upregulated in chronic lesions, reflecting astrogliosis. Reactive astrocytes in MS chronic lesions were mostly coupled with other astrocytes forming Cx43-Cx43 GJs and formed less Cx43-Cx47 GJs with oligodendrocytes (Markoullis et al., 2012b).

In $\mathrm{AD}$, astrocytic $\mathrm{Cx} 43$ and $\mathrm{Cx} 30$ expression was increased in $\mathrm{AD}$ post-mortem brain samples and in the APP/PS1 mouse model of AD, specifically around A $\beta$ plaques (Nagy et al., 1996; Mei et al., 2010). A $\beta$ peptide increases the propagation of $[\mathrm{Ca}]_{i}{ }^{2+}$ waves in astrocytes (Haughey and Mattson, 2003), a process in which Cxs are known to be involved (Scemes and Giaume, 2006). Low concentrations of monomerized $\mathrm{A} \beta_{1-40}$ impair gap junction communication in cultured rat astrocytes (Cruz et al., 2010). $\mathrm{A} \beta$-induced $\mathrm{HC}$ opening was reported in astrocytic, microglial, and neuronal cultures obtained from transgenic mice (Orellana et al., 2011b). Results showed that Cx43 and Pannexin 1 (Panx1) HCs are involved in microglia, while only $\mathrm{Cx} 43 \mathrm{HCs}$ are activated in astrocytes. Cx43 and Panx1 HCs were shown to be activated mostly in reactive astrocytes infiltrating $A \beta$ plaques, contributing to neuronal damage, in APP/PS1 mice (Yi et al., 2016). $A \beta_{25-35^{-}}$ induced HC activation leads to ATP and glutamate release from microglia and astrocytes, triggering $\mathrm{HC}$ opening in neurons with detrimental consequences in neuronal survival (Orellana et al., 2011b). Also, it was reported that in culture models, $A \beta$ not only triggers $\mathrm{HC}$ activation but also the activation of glial NMDA and P2X receptors, which in turn release ATP and glutamate, which then activate $\mathrm{HC}$ opening in neurons, leading to neuronal death (Koulakoff et al., 2012). Cx43 HC-mediated ATP release was reported in the APP/PS1 mouse model to further propagate the neurodegenerative process (Delekate et al., 2014). However, the implication of $\mathrm{Cx} 47$ in $\mathrm{AD}$ has not been investigated.

In the present report, we focused on the investigation of the astrocytic $\mathrm{C} x 43$ and $\mathrm{Cx} 30$ and the main partner of $\mathrm{Cx} 43$ in the $\mathrm{A} / \mathrm{O} \mathrm{GJs}, \mathrm{Cx} 47$, for the first time in the 5XFAD mouse model of $\mathrm{AD}$. We show increased immunoreactivity of $\mathrm{C} x 43$ and $\mathrm{Cx} 30$ at the microenvironment 
of $A \beta$ plaques by immunostaining analysis, suggesting a role for $\mathrm{Cx} 43$ in the progression of the disease, also confirmed by the analysis of brain protein extracts in 5XFAD mice. Furthermore, we demonstrate decreased immunoreactivity of $\mathrm{Cx} 47$, for the first time in a mouse model of $\mathrm{AD}$, indicating disruption of $\mathrm{A} / \mathrm{O} \mathrm{GJs}$, together with depletion in oligodendrocyte precursor cells (OPCs) and mature oligodendrocytes, possibly contributing to neuronal degeneration and $\mathrm{AD}$ progression.

\section{MATERIALS AND METHODS}

\section{Experimental Mice}

5XFAD mice overexpress high levels of mutant human APP (Swedish: K670N/M671L, Florida: I716V, London: V717I) and PSEN1 mutations (M146L, L286V mutations) under the presence of mouse Thy1 promoter, leading to rapid development of $A \beta$ pathology and increased production of $A \beta_{42}$ (Oakley et al., 2006). The 5XFAD transgenic mouse model of $\mathrm{AD}$ was purchased from Jackson Laboratory. Male 5XFAD mice were crossed with female SJL/B6 F1 mice and the offspring was used for all experiments. The offspring was divided in three age groups (3, 6 and 9 months of age, designated below as $3 \mathrm{M}, 6 \mathrm{M}$, and $9 \mathrm{M}$ groups, respectively) and both transgenic and age matched wild-type (WT) mice were used. Animals were maintained in pathogen-free (SPF) conditions, in a $12 \mathrm{~h}$ light/dark cycle and were always provided with food and water. Animal care, sacrifice and experimental protocols used in this project follow the EU guidelines (Council Directive 86/609/EEC) and were approved by the Cyprus Government's Veterinary Services (CY/EXP/PR.L1/2018).

\section{T-Maze Spontaneous Alternation Test}

The T-maze test is a behavioral test which quantifies cognitive deficits in mice by testing their spatial memory and exploratory behavior (Deacon and Rawlins, 2006). It is an enclosed wooden apparatus which consists of the start alley $(30 \mathrm{~cm}$ length $\times 10 \mathrm{~cm}$ width), two goal arms (30 cm length $\times 10 \mathrm{~cm}$ width), two guillotine doors which fit the maze and a central partition extending $7 \mathrm{~cm}$ into the start arm. The walls are $20 \mathrm{~cm}$ high. A thin layer of bedding (70\% new and 30\% old) was placed on the maze floor. The two guillotine doors were opened halfway, and the central partition was in place. Mice were placed in the start arm facing the wall and allowed to explore the start area. The selection of the goal arm (Left or Right) was recorded (all four appendages should enter the arm). As soon as the mouse had entered an arm, the guillotine door was closed, and the mouse was left in the arm for $30 \mathrm{~s}$. The central partition was then removed from the apparatus. The mouse was gently removed from the arm and placed again in the start arm. The selection of the goal arm (Left or Right) was recorded again. Finally, the mice were given a score after completing a trial $(0=$ entry in the same arm, $1=$ entry in the opposite arm (alternation), $2=$ no entry/entry exceeding the $90 \mathrm{~s}$ time limit). By repeating trials, mice should have higher tendency to enter the not previously visited arm. All mice completed
20 trials (4 trials per day) and the percentage of spontaneous alternation was calculated.

\section{Histology}

Mice were anesthetized intraperitoneally with Avertin and then transcardially perfused with normal saline followed by $4 \%$ paraformaldehyde (PFA). Half cerebrums were harvested, post-fixed with $4 \%$ PFA and cryopreserved in $20 \%$ sucrose in phosphate buffer (PB $0.1 \mathrm{M})$ overnight. Optimum cutting temperature (OCT) compound was then used as the tissue embedding medium. The embedded cerebrums were then placed in a dry-ice/acetone cooling bath and stored in $-80^{\circ} \mathrm{C}$. Twelve $\mu \mathrm{m}$-thick cryostat coronal sections were then obtained and stored in $-20^{\circ} \mathrm{C}$.

\section{Avidin-Biotin Complex (ABC) Immunohistochemistry}

Coronal brain hemi-sections were permeabilized in cold acetone for $10 \mathrm{~min}$, underwent quenching of endogenous peroxidase with $3 \% \mathrm{H}_{2} \mathrm{O}_{2}$ in methanol for $30 \mathrm{~min}$ and pre-treated with $70 \%$ formic acid (antigen retrieval) for $5 \mathrm{~min}$. Sections were then blocked at room temperature for $20 \mathrm{~min}$, with blocking solution [0.02\% normal horse serum (NHS) in PBS/Triton X-100 (0.5\%)], and incubated overnight at $4^{\circ} \mathrm{C}$ with anti- $\beta$-amyloid primary antibody (monoclonal 6E10, 1:400; Covance). Sections were then washed with PBS and incubated for $1 \mathrm{~h}$ with biotinylated secondary antibody which was detected with an avidin-biotinperoxidase complex (Vectastain Elite ABC kit, Vector Labs, PK-6102) and 3,3'-Diaminobenzidine (DAB, DAKO, K3468). The sections were then counterstained with hematoxylin and mounted with glycerol.

\section{Fluorescence Immunohistochemistry}

Sections were permeabilized in cold acetone for $10 \mathrm{~min}$, blocked at room temperature with blocking solution [5\% bovine serum albumin (BSA) in PBS/Triton X-100 (0.5\%)] and incubated overnight at $4^{\circ} \mathrm{C}$ with the following mouse monoclonal primary antibodies: anti- $\beta$-amyloid (6E10, 1:400; Covance), anti-glial fibrillary acidic protein (GFAP, Sigma, 1:400), anti-APC (CC1, Millipore, 1:50), anti-NeuN (Millipore, 1:400), anti-Cx47 (Invitrogen, 1:200), the following rabbit primary antibodies: anti- IBA1 (Biocare Medical, 1:500), anti-Cx43 (Cell Signaling, 1:50), anti-Cx30 (Thermo Fisher Scientific, 1:500), anti-Cx47 (Thermo Fisher Scientific, 1:500), anti-Cx32 (Thermo Fisher Scientific, 1:100) and anti-Olig2 (Millipore, 1:500) and the rat anti-PLP primary antibody (Prof. Reynold's lab, 1:10). Sections were then washed with PBS and incubated for $1 \mathrm{~h}$ with the respective secondary antibodies: Fluorescein (FITC) goat anti-mouse, 1:100, Alexa Fluor ${ }^{\circledR} 594$ goat anti-rabbit, 1:500, and rhodamine (TRITC) conjugated AffiniPure $\mathrm{F}\left(\mathrm{ab}^{\prime}\right)_{2}$ goat anti-rat, 1:2,000 (Jackson ImmunoResearch), stained with $4^{\prime}, 6^{\prime}$ diamidino-2-phenylindole (DAPI, Sigma-Aldrich) and mounted with fluorescent mounting medium (DAKO). Images were visualized by a Zeiss fluorescent microscope. To assess the astroglial and microglial activation, we measured the total area of GFAP and Ibal immunofluorescence as a percentage of the 
total image area using the Image $\mathrm{J}$ software. $\mathrm{NeuN}^{+}$neuronal numbers, Olig2 ${ }^{+}$cells (oligodendrocyte precursors and mature oligodendrocytes) and $\mathrm{CC}^{+}{ }^{+}$cells (mature oligodendrocytes) were counted per total area in $\mathrm{NeuN}$ and Olig2/CC1 stained sections, respectively.

\section{Semi-Quantification of Fluorescence Intensity of $\mathrm{C} \times 43, \mathrm{C} \times 30$, and $\mathrm{C} \times 47$ at the Sites of $A \beta$ Plaques}

In 3- and 9-months-old 5XFAD mice, $\mathrm{A} \beta / \mathrm{Cx} 43$ and $\mathrm{A} \beta / \mathrm{Cx} 30$ immunostaining of brain sections were used to measure the fluorescence intensity of $\mathrm{Cx} 43$ and $\mathrm{Cx} 30$ at the level of plaques. Multiple images of the cortex and thalamus were captured with a 20x objective using a Leica Fluorescence Microscope $(n=6$ mice per age). A $\beta$ plaques found close to blood vessels were not considered. The total number of $\mathrm{A} \beta$ plaques measured were: 353 plaques in $3 \mathrm{M}$ cortex, 472 plaques in $3 \mathrm{M}$ thalamus, 740 plaques in $9 \mathrm{M}$ cortex and 1101 plaques in $9 \mathrm{M}$ thalamus. Image $\mathrm{J}$ software was used to analyze these images. For each $\mathrm{A} \beta$ plaque, three oval selections (with $60^{\circ}$ rotation from each other) were made to cover the whole perimeter of the plaque and slightly outside of that perimeter. The mean fluorescence intensity of $\mathrm{Cx} 43$ and $\mathrm{Cx} 30$ was measured from the three oval selections at the level of each $A \beta$ plaque and compared with the $\mathrm{Cx}$ fluorescence intensity in five areas away from $A \beta$ plaques within the same image and significant differences $(p<0.05)$ between these values were identified by using the unpaired $t$-test (GraphPad Prism Software). From these measurements we were able to identify the percentage of $A \beta$ plaques which had increased, decreased or unchanged $\mathrm{Cx}$ immunoreactivity compared to control areas away from $A \beta$ plaques (Supplementary Figure 2). Also, the mean $\mathrm{Cx}$ fluorescence intensity at the level of $\mathrm{A} \beta$ plaques in 5XFAD mice was compared with the fluorescence intensity in areas away from $\mathrm{A} \beta$ plaques and with the $\mathrm{Cx}$ fluorescence intensity in WT mice (five different areas were measured per image). One-way ANOVA followed by Kruskal-Wallis test was used to detect any statistical significance between all age groups and the two genotypes.

Cx47 fluorescence intensity was measured in double immunostaining images for $\mathrm{A} \beta / \mathrm{Cx} 47$ in 3- and 9-months-old 5XFAD mice and compared with WT controls. Oligodendrocytes ( $n=31 /$ image) with Cx47-positive puncta were selected with $6.858 \mathrm{~mm}^{2}$ squares and the fluorescence intensity was measured after removing the background. The statistical analysis was performed by the unpaired $t$-test.

\section{RNA Extraction and Quantitative Real-Time PCR}

Cortex and thalamus were isolated from half cerebrums and RNA was extracted using the RNeasy lipid tissue mini kit (Qiagen). Tissues were homogenized with QIAzol lysis reagent and proteins were denatured with chloroform. DNase digestion was also performed, and total RNA was quantified using NanoDrop ND_100. TaqMan reverse transcription (RT) reagents were used for RT-PCR (final vol. $40 \mu \mathrm{l}$ ) in all samples $\left(25^{\circ} \mathrm{C}\right.$ for $10 \mathrm{~min}, 48^{\circ} \mathrm{C}$ for $30 \mathrm{~min}$, and $95^{\circ} \mathrm{C}$ for $5 \mathrm{~min}$ ). Also, quantitative real-time PCR was performed in all cDNAs to measure the expression of (Gjal (Cx43), GJb6 (Cx30), Gjc2 (Cx47), and Gjb1 (Cx32) genes compared to the expression of Tubb4a (Tubulin, house-keeping gene) using the following Taqman Gene Expression assays: Cx43: Mm01179639_m1, Cx30: Mm00433661_s1, Cx47: Mm00519131-s1, Cx32: Mm01950058s1, and Tubulin: Mm00726185_s1. A 7900HT Real-Time PCR System (Applied Biosystems, hold at $55^{\circ} \mathrm{C}$ for $2 \mathrm{~min}$ and at $95^{\circ} \mathrm{C}$ for $10 \mathrm{~min}$, followed by 40 cycles at $95^{\circ} \mathrm{C}$ for $15 \mathrm{~s}$ and at $60^{\circ} \mathrm{C}$ for $1 \mathrm{~min}$ ) was used for this purpose. Triplicates from each cDNA sample were loaded (200 ng) along with 1 $\mu l$ of Taqman Gene Expression assay and $10 \mu \mathrm{l}$ of Taqman Gene Expression Master mix in a final volume of $20 \mu \mathrm{l}$. Cycle thresholds (Cts) of genes of interest were normalized against tubulin and mRNA levels were calculated in 5XFAD and WT mice and shown as fold induction values $\left(2^{-\Delta \Delta \mathrm{Ct}}\right)$ compared to WT control mice.

\section{Immunoblot Analysis}

Mice were sacrificed and the cortex and thalamus were harvested from half cerebrums. The tissues were homogenized in ice-cold RIPA buffer (1\% NP-40, 0.5\% $\mathrm{C}_{24} \mathrm{H}_{39} \mathrm{Na}_{4}, 0.1 \%$ SDS, $2 \mathrm{mM}$ EDTA) dissolved in $1 \times$ PBS along with a protease inhibitor cocktail (Roche) and centrifuged for $20 \mathrm{~min}$ at $4^{\circ} \mathrm{C}$. Protein concentration was measured with bicinchoninic acid (BCA) assay (Smith et al., 1985) and $100 \mu \mathrm{g}$ were mixed with $4 \mathrm{x}$ laemli buffer (Biorad). Tissue lysates were loaded in 12\% SDS-PAGE [ $\mathrm{ddH}_{2} 0,30 \%$ acrylamide-bis (29:1), 1.5M TrisCL $\mathrm{pH} 8.8,10 \% \mathrm{SDS}, 10 \% \mathrm{APS}$, Temed] and transferred to a Hybond PVDF blotting membrane (Life Sciences) using a semi-dry unit. The membrane was blocked in blocking solution $[5 \%$ non-fat skimmed milk in PBS containing $0.1 \%$ Tween-20 (PBS-T)] for $1 \mathrm{~h}$ at room temperature and then incubated overnight at $4^{\circ} \mathrm{C}$ with the following mouse primary antibodies: anti-Cx43 (Millipore, 1:1,000) and antiTubulin-E7 (DSHB, 1:4,000) and the rabbit anti-Cx30 (Thermo Fisher Scientific, 1:500). After $15 \mathrm{~min}$ washes in PBS-T, membranes were incubated for $1 \mathrm{~h}$ at room temperature with a goat anti-mouse or anti-rabbit HRP-conjugated secondary antibody (Jackson Immunoresearch, 1:3,000). The bound antibody was visualized by enhanced chemiluminescence system (ECL, GE Healthcare Life Sciences), protein expression was normalized against tubulin and band intensity was quantified using Image J.

\section{Statistical Analysis}

All data in graphs are expressed as the mean and error bars indicate the standard error of the mean (SEM). Normal distribution of data was evaluated, and the statistical tests performed were the following: One-way ANOVA followed by Sidak's or Kruskal-Wallis multiple comparisons test and unpaired $t$-test. Values of $p<0.05$ were considered significant. Details showing which statistical test was performed in each experiment are reported in the figure legends. 


\section{RESULTS}

\section{Amyloid-Beta Pathology in 5XFAD Mice}

The localization of $A \beta$ deposits was investigated at 3, 6, and 9 months of age. DAB immunohistochemistry was performed in 5XFAD mice as well as in their age-matched WT littermate controls. $A \beta$ accumulation in 5XFAD mice has been shown to progress with age (Oakley et al., 2006). Likewise, we observed in 3 - months-old 5XFAD mice a few $\mathrm{A} \beta$ deposits in the cortex (layer $\mathrm{VI})$ and in the thalamus. $\mathrm{A} \beta$ deposition gradually increased with age and larger deposits were observed in 9- months-old 5XFAD mice compared to 3- and 6-months-old animals (Figures 1A,B). Plaques at 6 and 9 months of age covered all cortical layers and the whole retrosplenial area of the cortex but were found most prominently in the layers V and VI of all other cortical areas (posterior parietal, primary somatosensory, auditory, temporal, ectorhinal, perirhinal, and entorhinal area). By 9 months of age the larger sized plaques were localized in cortical layer $\mathrm{V}$. Moreover, at 6 and 9 months of age $A \beta$ deposits were also found in the hippocampus mainly in the stratum oriens of the CA1 area and in the molecular and polymorph layers of the dentate gyrus. They also covered the whole thalamic area. WT mice showed no deposits in all ages.

\section{Neuronal Loss and Hippocampal Impairment in 6- and 9-Months-Old 5XFAD Mice}

$A \beta$ plaques in the brain can contribute to loss of function and neuronal death either directly or indirectly by disrupting the communication between neurons (Parihar and Brewer, 2010). Therefore, we investigated whether mature neurons were affected by the AD pathology in this mouse model. Since the majority of $A \beta$ plaques were localized in the cortical layer $V$ and thalamus, as shown above, we assessed possible neuronal loss in these areas. Neurons were counted from an area of 260 and $346 \mathrm{~mm}^{2}$ in the cortical layer $\mathrm{V}$ and thalamus, respectively. Immunostaining with NeuN antibody (Figures 2A-D) showed that 3-monthsold 5XFAD and WT mice had similar numbers of neurons in cortical layer V (5XFAD: $333 \pm 19 \mathrm{NeuN}^{+}$cells per area, WT: $322 \pm 9 \mathrm{NeuN}^{+}$cells per area). However, 6- and 9-months-old 5XFAD mice had significantly lower numbers of mature neurons $\left(246 \pm 18 \mathrm{NeuN}^{+}\right.$cells per area and $236 \pm 10$, respectively) compared to those at 3 -months of age $\left(333 \pm 19 \mathrm{NeuN}^{+}\right.$cells per area). Also, the number of mature neurons in 9-months-old 5XFAD mice was significantly lower $\left(236 \pm 10 \mathrm{NeuN}^{+}\right.$cells per area) compared to WT mice of the same age $\left(300 \pm 6 \mathrm{NeuN}^{+}\right.$ cells per area). In the thalamus, neuronal loss was significant only in 9-months-old (96 $\pm 9 \mathrm{NeuN}^{+}$cells per area) compared to 3months-old 5XFAD mice (146 $\pm 7 \mathrm{NeuN}^{+}$cells per area). Taken together, these data indicate, progressive neuronal loss in cortical layer $\mathrm{V}$ and to a lesser degree in the thalamus, associated with progressive $\mathrm{A} \beta$ deposition in older $5 \mathrm{XFAD}$ mice.

Furthermore, to assess the hippocampus-depended working memory and spatial learning of 5XFAD mice we calculated the spontaneous alternation of mice with a T-maze apparatus (Figure 2E). This behavioral test measures the exploratory behavior of animals, i.e., the preference to enter a new arm of the maze rather than the arm they have visited before. 5XFAD mice at 6 months of age showed reduced alternation compared to their age-matched WT controls. Similarly, 9months-old 5XFAD mice showed reduced alternation compared to WT controls of the same age, as well as compared to 6months-old 5XFAD mice. Thus, 6- and 9-months-old 5XFAD mice show progressive deficits in memory function due to hippocampal impairment.

\section{Increased Gliosis in the Brain of Older 5XFAD Mice}

A major contributor to neurodegeneration in $\mathrm{AD}$ is also neuroinflammation, which is known to be associated with the progression of the disease. Astrocytes and microglia surround $A \beta$ plaques and become reactive propagating inflammatory signals (Fakhoury, 2017). Therefore, anti-GFAP and anti-Ibal antibodies were used to evaluate the degree of microglia activation and astrogliosis (Kamphuis et al., 2014; Navarro et al., 2018).

Immunohistochemistry experiments in 5XFAD mice have revealed some morphological characteristics of glial cells in both brain areas at each age [cortical layer V: retrosplenial (RSP) area, primary and secondary motor areas (MOp, MOs); thalamus: posterior complex (PO) and ventral posteromedial (VPM) nucleus of the thalamus]. Astrocytes in the cortex and thalamus of 3-months-old 5XFAD mice were moderately reactive with an apparent GFAP upregulation (Figures 3A,B). In addition, at the ages of 6 and 9 months, 5XFAD mice showed severe reactive astrogliosis in both brain areas compared to the 3months-old 5XFAD mice, with GFAP upregulation, cytoskeletal hypertrophy and overlap of astrocytic processes. In contrast, reactive astrocytes were extremely rare in WT mice at all ages. Likewise, microglia at all ages of 5XFAD mice, were shown to be in an activated state, characterized by cell body hypertrophy and shortened processes, in contrast to WT littermates showing lack of microglia activation.

By quantifying the percentage of the total area covered by astrocytes and microglia in the immunostaining images, we confirmed that in both brain areas the levels of GFAP ${ }^{+}$astrocytes in 6- and 9-months old 5XFAD mice were increased (cortex: $11.39 \% \pm 0.71$ and $11.75 \% \pm 1.49$, respectively, thalamus: $14.52 \% \pm 0.90$ and $15.29 \% \pm 1.82$, respectively) compared to 3-months-old 5XFAD mice (cortex: $4.52 \% \pm 0.67$, thalamus: $5.23 \% \pm 0.81$ ), whereas the levels were similar when comparing 6- and 9-months-old mice (Figures 3C,D). As expected, WT mice of all ages showed very low levels of $\mathrm{GFAP}^{+}$immunoreactivity in the cortex and thalamus.

Furthermore, in the cortex and thalamus, $\mathrm{Iba}^{+}$microglia levels (Figures 3E,F) were slightly increased at 6- and 9-monthsold 5XFAD mice (cortex: $7.20 \% \pm 0.49$ and $6.84 \% \pm 0.81$ respectively, thalamus: $8.84 \% \pm 0.65$ and $7.58 \% \pm 0.57$, respectively) compared to the 3-months-old mice (cortex: $4.55 \% \pm 0.28$, thalamus: $4.59 \% \pm 0.57$ ). However, the levels of $\mathrm{Ibal}^{+}$microglia were similar among 6- and 9-months-old 5XFAD mice. In both the cortex and thalamus 5XFAD mice of all age groups showed significantly increased levels of Iba $1^{+}$ 
A
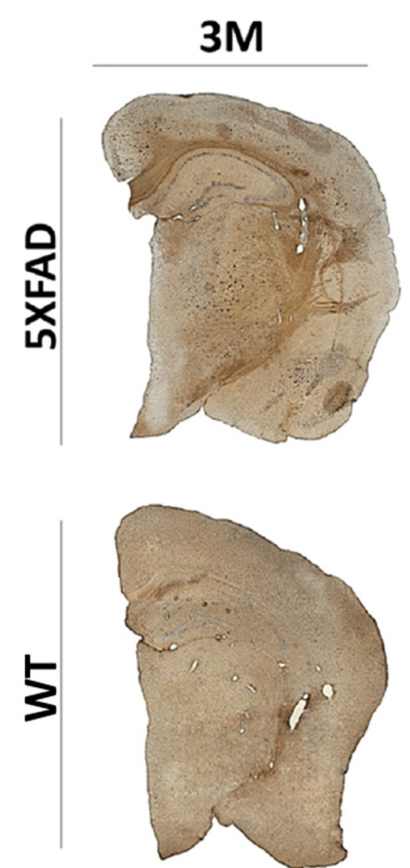

B

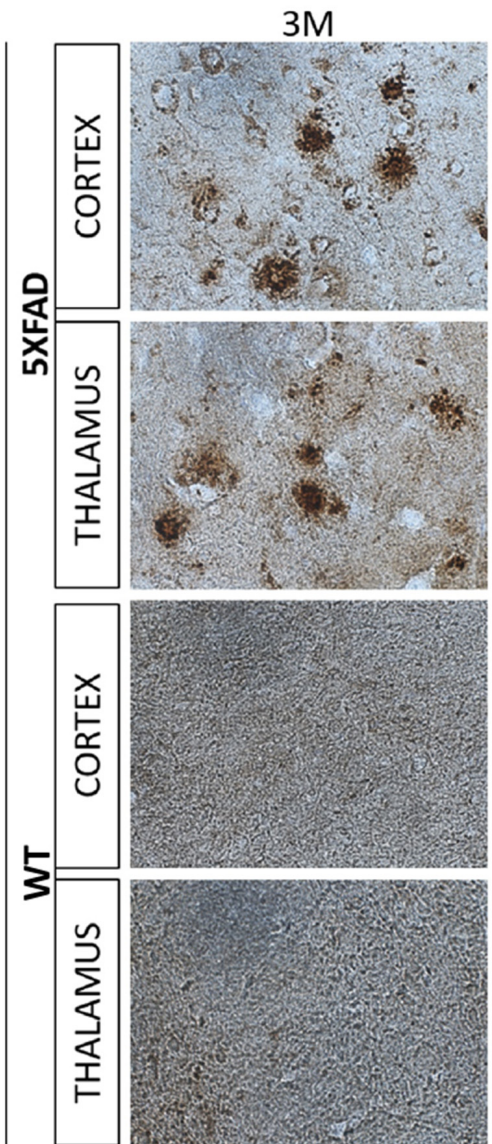

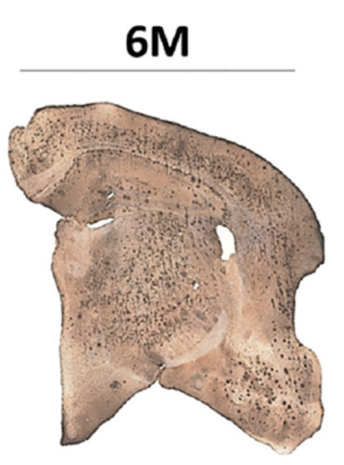
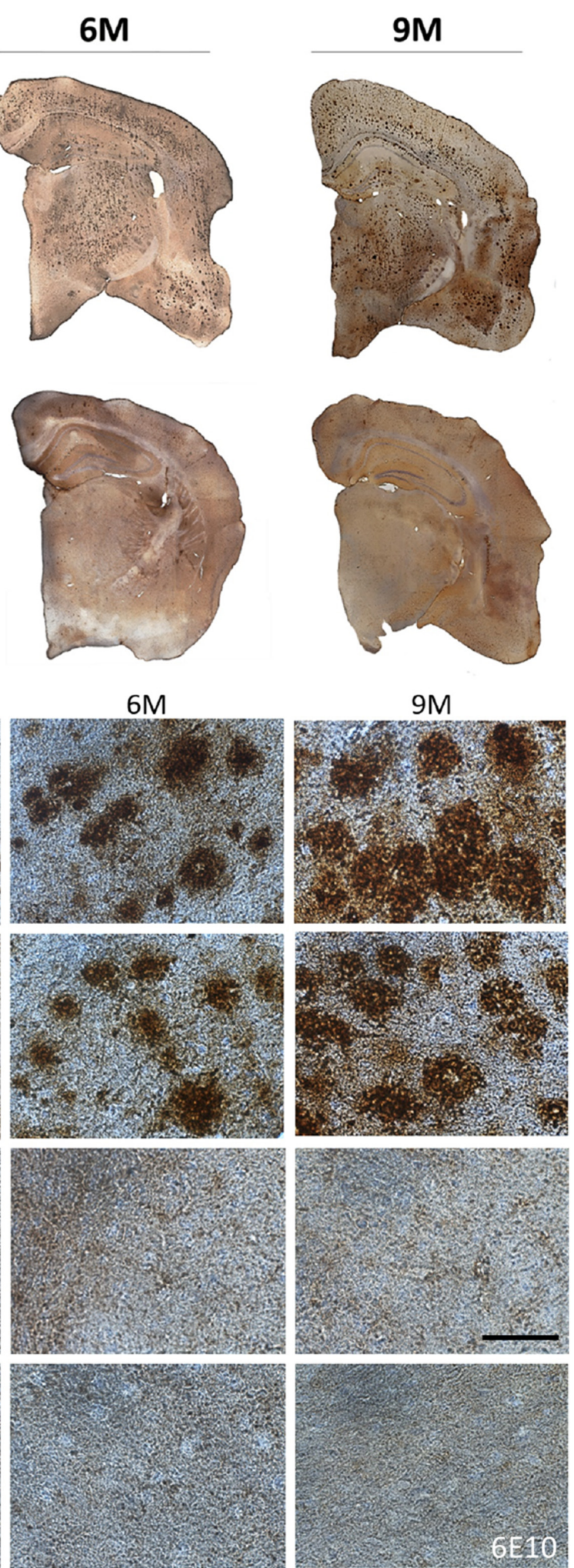

FIGURE 1 | Progressive formation of A $\beta$ plaques in 5XFAD mice. Brain DAB immunohistochemistry showed A $\beta$ deposition in three age groups of 5 XFAD mice (3, 6 , and 9 months). (A) Coronal brain hemi-sections (12 $\mu \mathrm{m}$ thick) were stained with 6E10 primary antibody followed by DAB chromogen to reveal individual plaques (brown dots) in the cortex, thalamus and hippocampus. (B) A $\beta$ plaque deposition increased tremendously with age as shown in higher magnification images of 5XFAD as opposed to WT mice in both brain areas. Scale bar $=50 \mu \mathrm{m}$ in (B). 


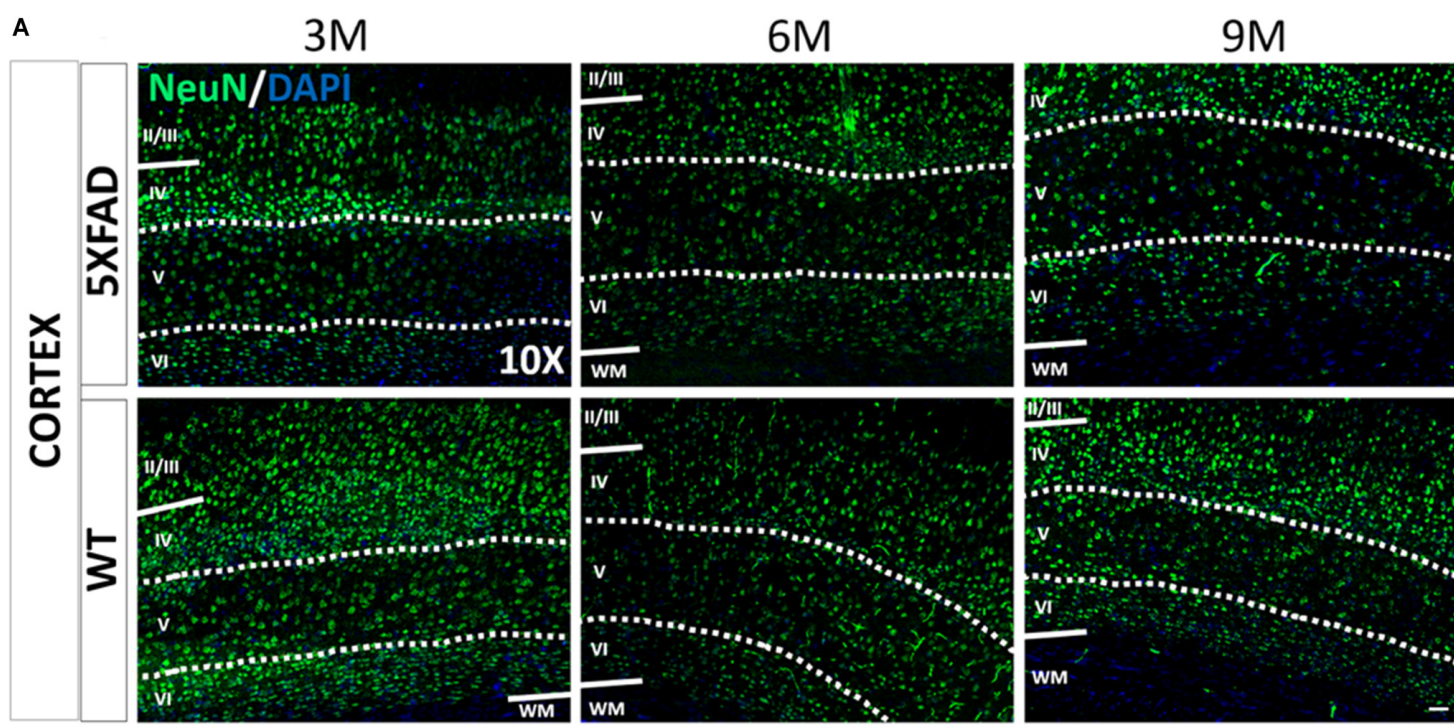

B

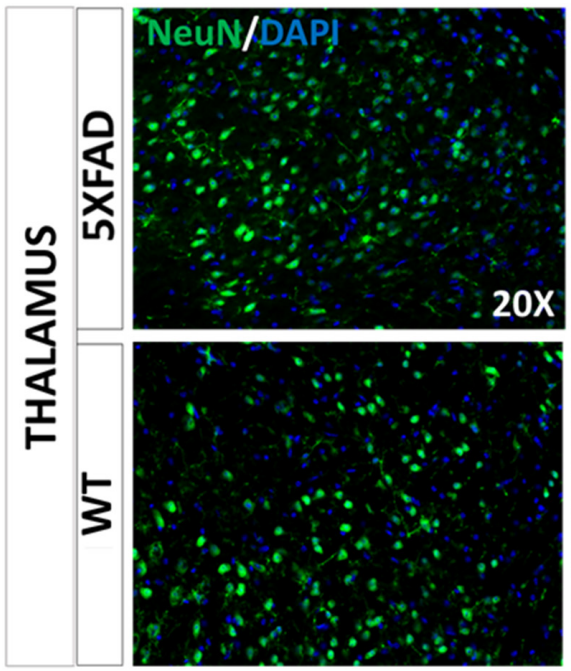

C
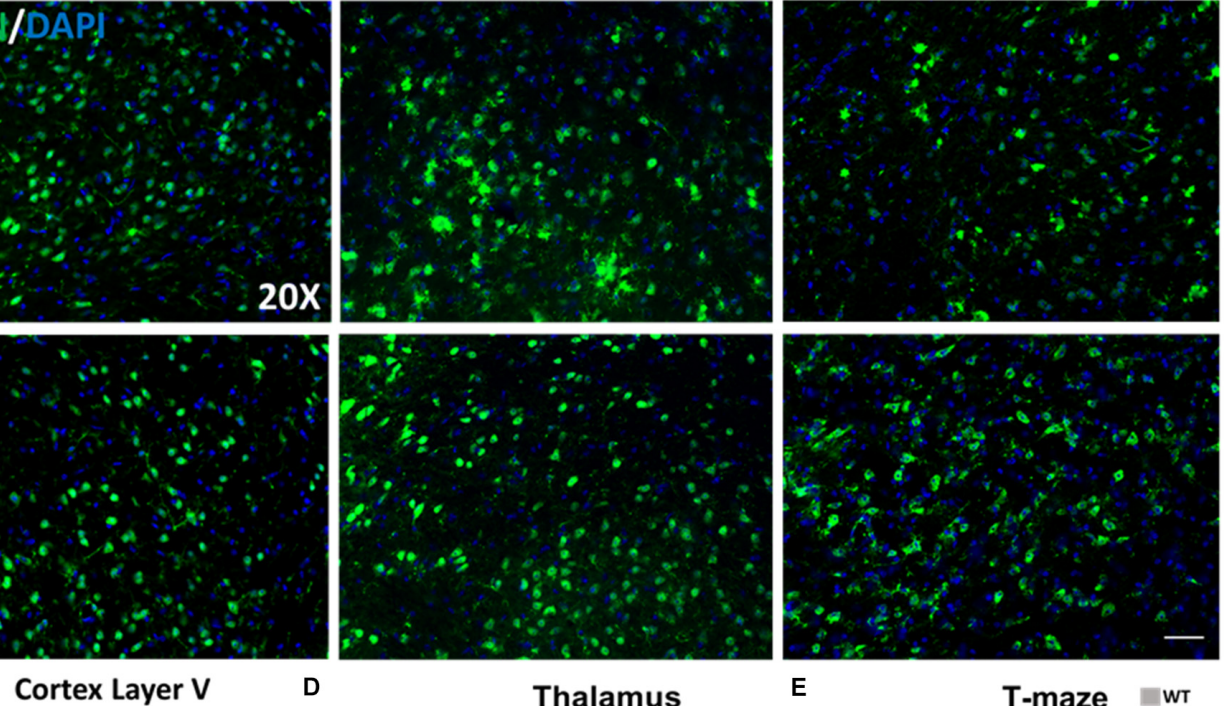

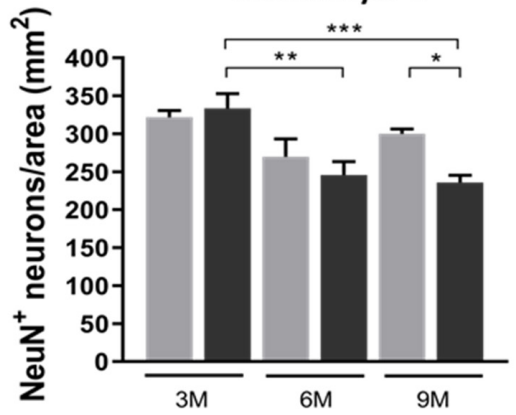

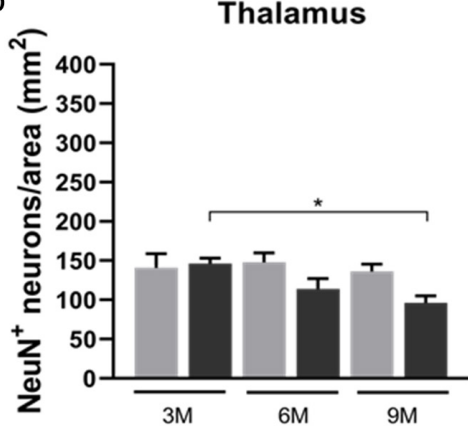
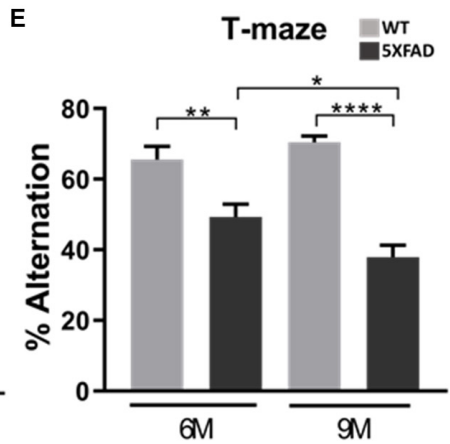

FIGURE 2 | Neuronal loss and cognitive decline in 5XFAD mice. (A) Immunofluorescence staining of cortical areas from 5XFAD and WT mice with neuronal marker $\mathrm{NeuN}^{+}$(green) labeling neurons. Cell nuclei are counterstained with DAPI (blue). Cortical layer $\mathrm{V}$ is indicated with dotted lines and limits of other cortical layers are indicated with white lines. (B) Immunofluorescence staining of thalamic areas from 5XFAD and WT mice with neuronal marker NeuN ${ }^{+}$(green) labeling neurons.

(C) Quantification of the mean number of neurons in cortical layer V indicates neuronal loss in 6- and 9-months-old compared to 3-months-old 5XFAD mice. (D) In the thalamus, quantification of the mean number of neurons shows there is neuronal loss in 9-months-old 5XFAD compared to 3-months-old 5XFAD. [One-way ANOVA followed by Sidak's multiple comparisons test, 5XFAD mice/age $(n=6)$, WT mice/age $(n=6)]$. (E) T-maze behavioral test indicates reduced alternation percentage in 5XFAD mice in both age groups [unpaired $t$-test, 6M 5XFAD mice $(n=20)$, 6M WT mice $(n=18)$, 9M 5XFAD mice $(n=12)$, 9M WT mice $(n=12)$ ]. Graphs show the mean and error bars indicate the standard error of the mean (SEM). Significance is given as: ${ }^{\star} p=0.0332,{ }^{\star *} p=0.0021,{ }^{\star \star \star} p=0.0002$,

${ }^{\star * \star *} p<0.0001$. Scale bars $=50 \mu \mathrm{m}$ in $(\mathbf{A}, \mathbf{B})$. 

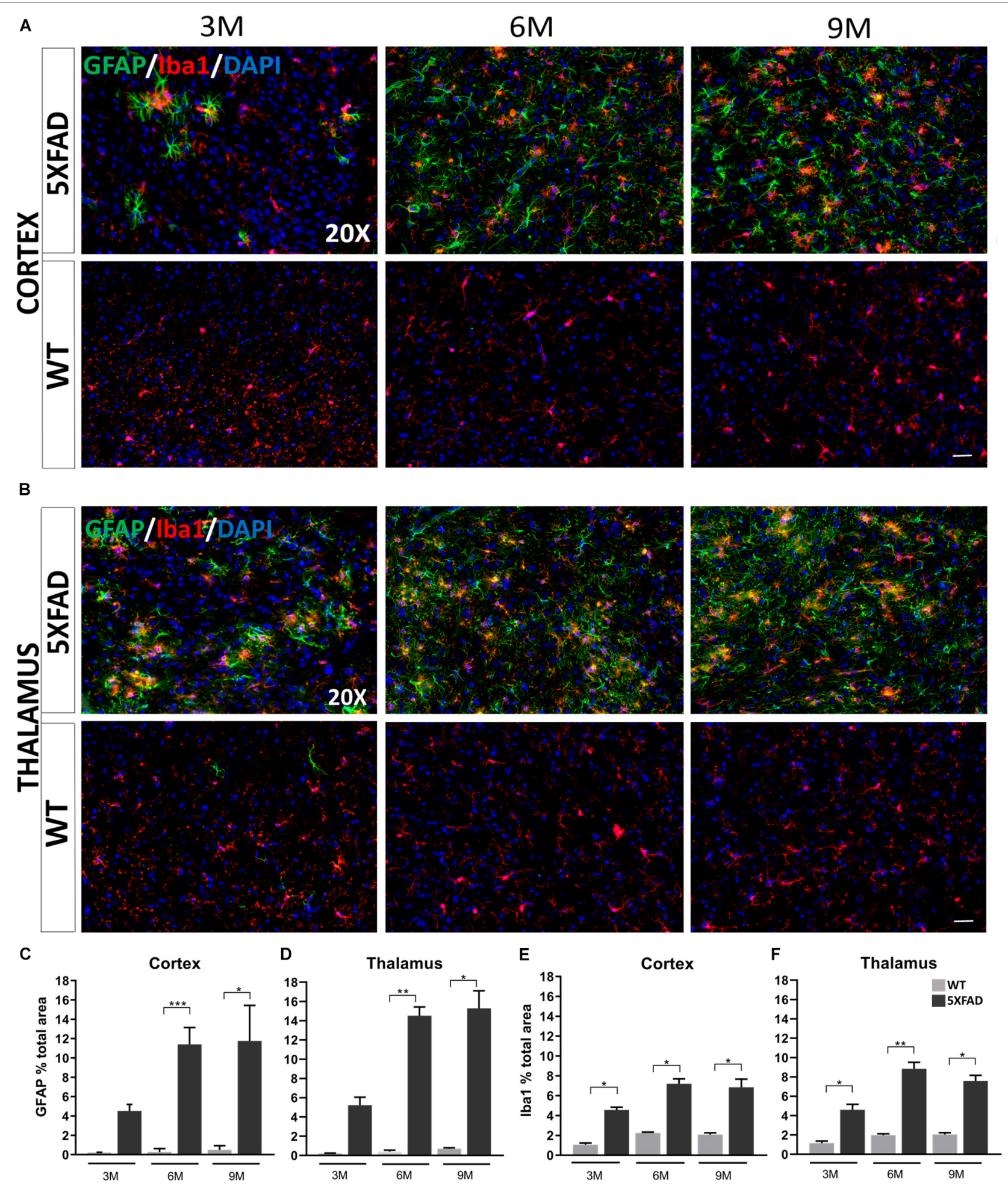

FIGURE 3 | Progressive inflammation and astrogliosis in the RSP, MOp and MOs areas of cortical layer V and in the PO and VPM nucleus of the thalamus in 5XFAD mice. (A,B) Double immunofluorescence staining of cortical and thalamic areas from 5XFAD and WT mice, with astrocytic marker, GFAP (green) and microglial marker, Iba1 (red). 5XFAD mice showed increased gliosis in both brain areas in older ages, while WT mice showed no astrogliosis. Quantification of the percentage of the total area covering GFAP ${ }^{+}$astrocytes (C,D) and Iba1 ${ }^{+}$microglia (E,F) in both brain areas confirmed increased astrogliosis reaching plateau in 9-months-old 5XFAD mice. The statistical analysis was performed by one-way ANOVA followed by Kruskal-Wallis multiple comparisons test [5XFAD mice/age ( $n=6$ ), WT mice/age $(n=6)]$. Graphs show the mean and error bars indicate the standard error of the mean (SEM). Significance is given as: ${ }^{\star} p=0.0332,{ }^{\star \star} p=0.0021,{ }^{\star \star \star} p=0.0002$. Scale bars $=50 \mu \mathrm{m}$ in $(\mathbf{A}, \mathbf{B})$. 
microglia (cortex: 3M: $4.55 \% \pm 0.28,6 \mathrm{M}: 7.20 \% \pm 0.49,9 \mathrm{M}$ : $6.84 \% \pm 0.81$; thalamus: $3 \mathrm{M}: 4.59 \% \pm 0.57,6 \mathrm{M}: 8.84 \% \pm 0.65$, 9M: $7.58 \% \pm 0.57)$ compared to their age-matched WT littermates (cortex: 3M: $1.05 \% \pm 0.17,6 \mathrm{M}: 2.24 \% \pm 0.08,9 \mathrm{M}$ : $2.07 \% \pm 0.17$; thalamus: $3 \mathrm{M}: 1.15 \% \pm 0.21,6 \mathrm{M}: 1.97 \% \pm 0.14$, 9M: $2.04 \% \pm 0.18)$.

\section{Increased Immunoreactivity of Cx43 and Cx30 Around A $\beta$ Plaques in 5XFAD Mice}

Astrocytes form highly organized networks in the CNS, maintaining communication via GJs or HCs (Xing et al., 2019). Since reactive astrocytes are involved in inflammatory responses, surrounding $\mathrm{A} \beta$ plaques in $\mathrm{AD}$ (Perez-Nievas and SerranoPozo, 2018) we further investigated the expression of the major astrocytic Cxs ( $\mathrm{Cx} 43$ and $\mathrm{Cx} 30)$ which compose the GJs or HCs in 5XFAD mice. However, we cannot exclude that some of the Cx43 could be expressed in microglia or non-GFAP astrocytes (Supplementary Figure 1). We examined their expression in the RSP, MOp and MOs areas of cortical layer V and in the PO and VPM nucleus of the thalamus in 3- and 9-months-old 5XFAD mice, where neuronal loss was observed in older mice.

Double immunostainings for $\mathrm{A} \beta / \mathrm{Cx} 43$ and $\mathrm{A} \beta / \mathrm{Cx} 30$ were performed (Figures 4A,B) and the fluorescence intensity of both Cxs was measured in the area around the perimeter of $A \beta$ plaques and away from $\mathrm{A} \beta$ plaques, compared to the corresponding areas of aged-matched WT controls. Results were categorized in three different $\mathrm{Cx}$ immunoreactivity profiles around $\mathrm{A} \beta$ plaques: increased, unchanged, and decreased immunoreactivity compared to areas away from $A \beta$ plaques. The percentages of $A \beta$ plaques having each of those profiles were calculated (Supplementary Figure 2).

In the cortex and thalamus, $\mathrm{Cx} 43$ immunoreactivity was higher in 9-months-old 5XFAD mice and especially around $\mathrm{A} \beta$ plaques (cortex: 309,658 $\pm 10,389$ a.u., thalamus: 209,265 $\pm 4,893$ a.u.) compared to 3-months-old mice (cortex: 53,608 $\pm 2,737$ a.u., thalamus: $55,192 \pm 1,858$ a.u.). There was also significantly higher $\mathrm{Cx} 43$ immunoreactivity at 9 months around the area of plaques compared to areas away from plaques (cortex: 85,664 \pm 7,541 a.u., thalamus: 94,554 \pm 6,280 a.u., Figures 4C,D). In contrast, $\mathrm{Cx} 43$ immunoreactivity in the corresponding areas of 9-months-old WT mice (cortex: 47,447 $\pm 2,596$ a.u., thalamus: $65,454 \pm 3,203$ a.u.) and in areas far from $A \beta$ plaques in $5 X F A D$ mice (cortex: 85,664 \pm 7,541 a.u., thalamus: 94,554 $\pm 6,280$ a.u.) showed no significant difference, although there was a tendency to increase in 5XFAD non-plaque areas. These results confirmed that $\mathrm{Cx} 43$ channels were increased specifically in the microenvironment of $\mathrm{A} \beta$ plaques and not in areas that were far away. The expression of Cx43 in 3-months-old 5XFAD mice around plaques in both brain regions (cortex: 53,608 $\pm 2,737$ a.u., thalamus: $55,192 \pm 1,858$ a.u.) was similar to the expression of Cx43 in areas away from plaques (cortex: 39,093 $\pm 1,700$ a.u., thalamus: $51,797 \pm 2,280$ a.u.) and in areas of WT mice of the same age (cortex: 19,893 $\pm 1,134$ a.u., thalamus: 25,228 $\pm 1,565$ a.u.) as well as in areas of 9-months-old WT mice (cortex: 47,447 \pm 2,596 a.u., thalamus: 65,454 \pm 3,203 a.u.). Thus, increased $\mathrm{Cx} 43$ expression around $\mathrm{A} \beta$ plaques likely occurs at later stages of $\mathrm{AD}$ pathology as a result of progressive astrogliosis and neurodegeneration.

Similar to Cx43, Cx30 immunoreactivity (Figures 4E,F) was increased around $\mathrm{A} \beta$ plaques in 9-months-old 5XFAD mice (cortex: $234,427 \pm 7,560$ a.u., thalamus: $143,549 \pm 3,405$ a.u.) compared to 3-months-old 5XFAD mice (cortex: 72,913 $\pm 2,382$ a.u., thalamus: $80,219 \pm 2,478$ a.u.). In the cortex, $\mathrm{Cx} 30$ immunoreactivity was also increased around $\mathrm{A} \beta$ plaques $(234,427 \pm 7,560$ a.u.) compared to areas away from plaques $(72,290 \pm 3,769$ a.u.) and in corresponding areas of WT controls $(28,749 \pm 1,152$ a.u.). However, in the thalamus of 9-monthold 5XFAD mice there was no significant difference between the immunoreactivity of $\mathrm{Cx} 30$ around $\mathrm{A} \beta$ plaques $(143,549 \pm 3,405$ a.u.) and areas away from $A \beta$ plaques (103,272 $\pm 7,420$ a.u.). Cx30 immunoreactivity in those two areas was significantly increased compared to areas in WT controls $(31,984 \pm 1,895$ a.u.). These results indicate that $\mathrm{Cx} 30$ was increased around $\mathrm{A} \beta$ plaques in the cortices of aged 5XFAD mice, but this did not occur in the thalamus, where $\mathrm{Cx} 30$ was more diffusely increased both around and in areas away from plaques. At 3 months of age, in both brain regions of 5XFAD mice, Cx30 was slightly increased in areas away from plaques (cortex: 86,273 $\pm 2,519$ a.u., thalamus: $114,374 \pm 5,635$ a.u.) compared to areas around plaques (cortex: $72,913 \pm 2,382$ a.u., thalamus: 80,219 $\pm 2,478$ a.u.) and areas in WT controls (cortex: 52,192 \pm 2,764 a.u., thalamus: $73,084 \pm 2,639$ a.u.). These findings suggest that both astrocyte $\mathrm{Cxs}$ are increased as a result of $\mathrm{AD}$ pathology, but $\mathrm{Cx} 43$ is more prominent than $\mathrm{Cx} 30$ in reactive astrocytes especially around $\mathrm{A} \beta$ plaques.

\section{Increased Cx43 Protein and Unchanged Cx30 Protein Levels in 5XFAD Mice of All Ages}

To further corroborate the results of the immunofluorescence experiments, indicating specific alterations of astrocytic Cxs and in particular of $\mathrm{Cx} 43$ more than $\mathrm{Cx} 30$ in the microenvironment of $A \beta$ plaques in older 5XFAD mice, we investigated the mRNA and protein levels of these two astrocytic Cxs in the cortex and thalamus of these mice.

Interestingly, in both brain areas, $\mathrm{Cx} 43 \mathrm{mRNA}$ levels in all three age groups of 5XFAD mice, were significantly lower compared to their aged-matched WT controls (Figures 5A,C). Moreover, mRNA levels were significantly lower in 3-compared to 9-months-old 5XFAD mice, in both brain areas but in the thalamus this significance was stronger than in the cortex. In contrast, immunoblot experiments showed increased levels of Cx43 protein in 3- and 9-months-old 5XFAD mice compared to their aged matched WT controls, in the cortex as well as in the thalamus (Figures 5B,D and Supplementary Figure 3, shows original gels), in keeping with the immunostaining results. This inverse correlation between mRNA and protein levels could reflect the complex regulatory mechanisms that underlie transcription and translation such as transcriptional modifications (Yan et al., 2018).

On the other hand, Cx30 mRNA levels in both brain areas from all three age groups of 5XFAD mice showed no 


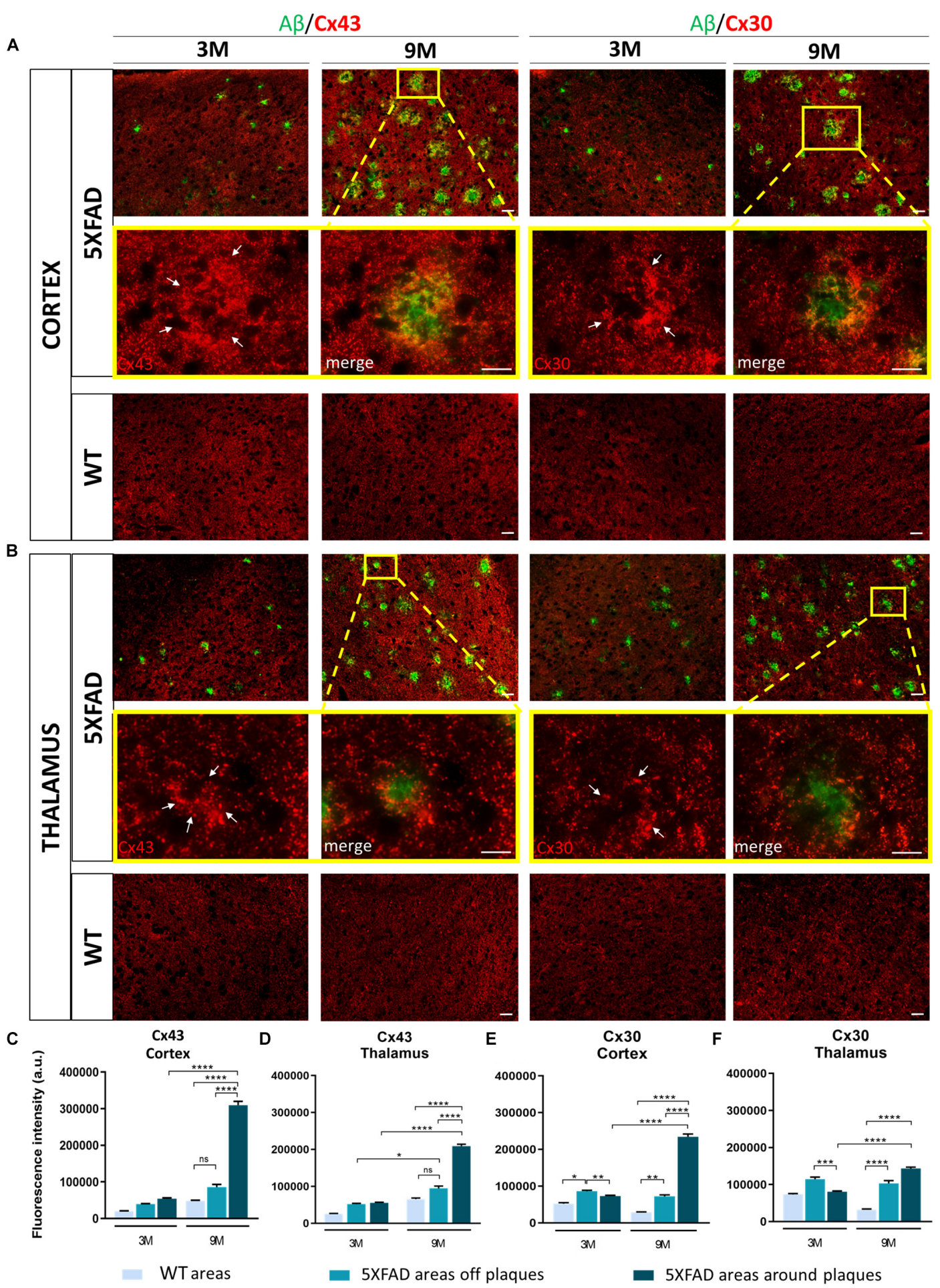

FIGURE 4 | Increased immunoreactivity of $\mathrm{C} \times 43$ and $\mathrm{C} \times 30$ in areas around $A \beta$ plaques in the RSP, MOp and MOs areas of cortical layer V and in the PO and VPM nucleus of the thalamus of 3 and 9-months-old 5XFAD mice. Double immunofluorescence staining of cortical and thalamic areas from 5XFAD and WT mice, with A $\beta$ antibody (clone 6E10, green) and Cx43 or Cx30 (red). (A,B) 5XFAD mice at the age of 9-months showed increased immunoreactivity of Cx43 and Cx30 in the perimeter of $\mathrm{A} \beta$ plaques. Higher magnification images clearly show this phenomenon. (C-F) Quantification of the fluorescence intensity of $\mathrm{C} \times 43$ and $\mathrm{C} \times 30$ in areas around and away from A $\beta$ plaques in 5XFAD mice and in areas in WT mice. Increased immunoreactivity of $\mathrm{C} \times 43$ and $\mathrm{C} \times 30$ was detected in the perimeter of A 3 plaques compared to areas off A $\beta$ plaques in 5XFAD mice and in WT areas. The statistical analysis was performed by one-way ANOVA followed by Kruskal-Wallis multiple comparisons test [5XFAD mice/age $(n=6)$, WT mice/age $(n=6)]$. Graphs show the mean and error bars indicate the standard error of the mean (SEM). Significance is given as: ${ }^{*} p=0.0332,{ }^{* *} p=0.0021,{ }^{* \star *} p=0.0002,{ }^{\star * \star *} p<0.0001$. Scale bars $=50 \mu \mathrm{m}$ in $(\mathbf{A}, \mathbf{B}) ; 25 \mu \mathrm{m}$ in higher magnification insets. 


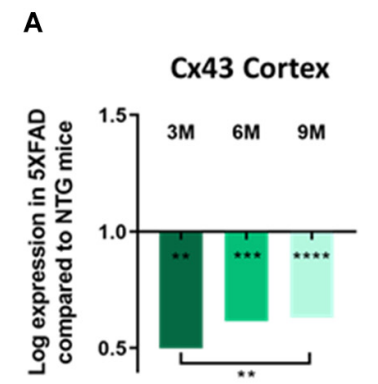

C

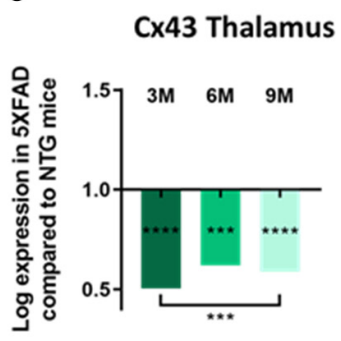

E

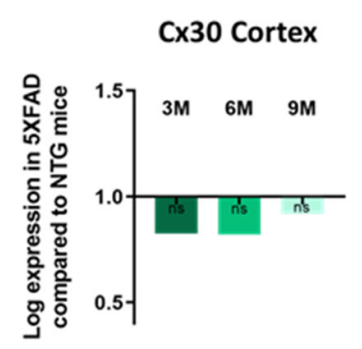

G Cx30 Thalamus

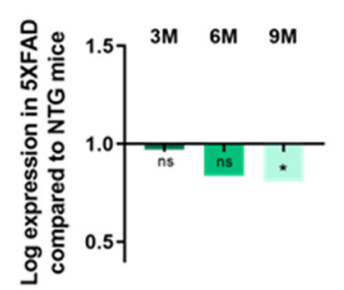

B
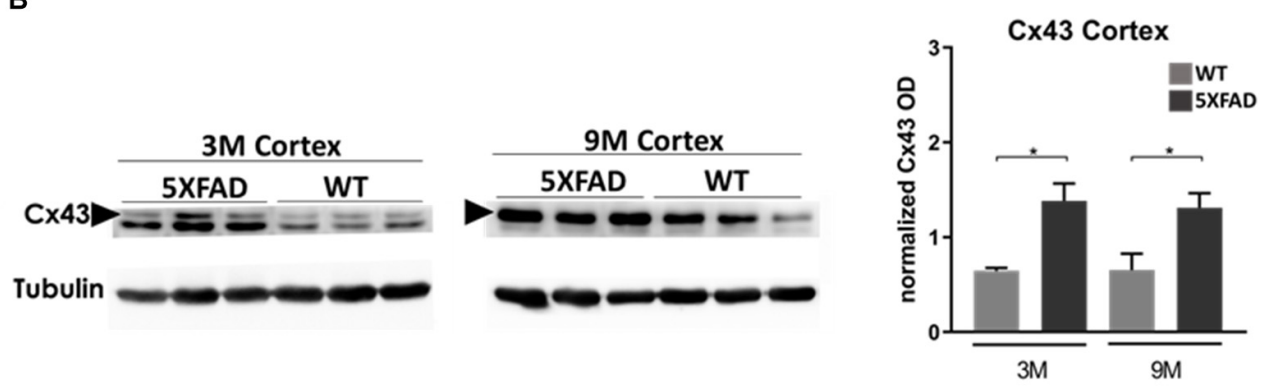

D

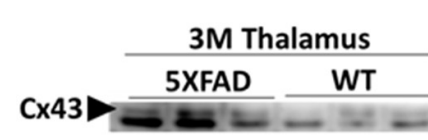

Tubulin
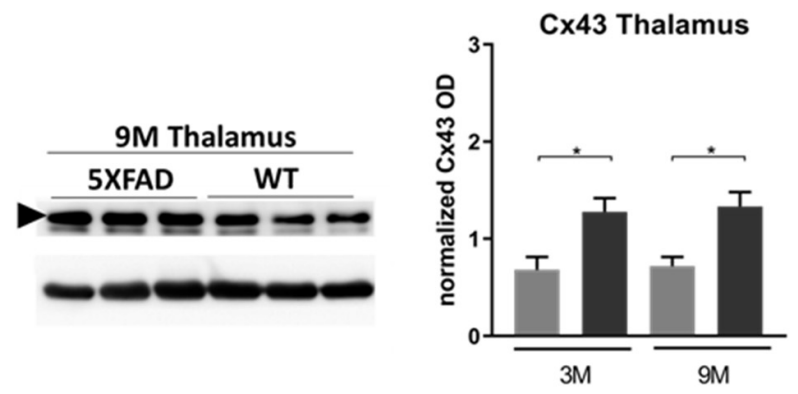

F

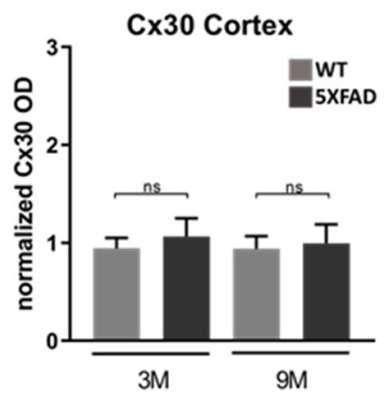

H

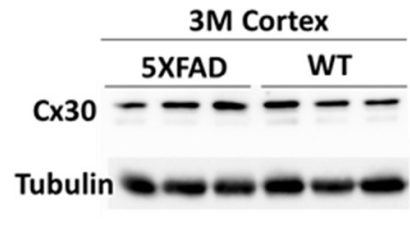

9M Cortex
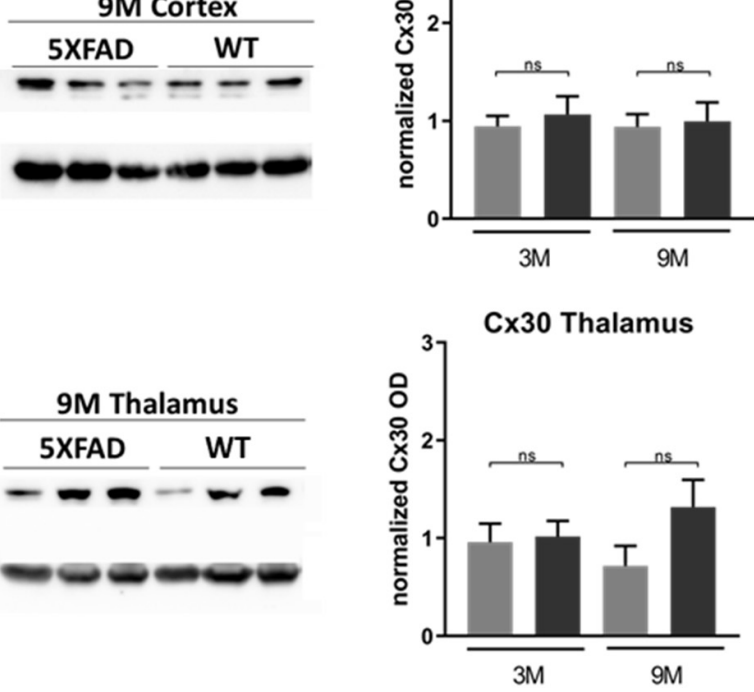

FIGURE 5 | CX43 and CX30 mRNA and protein levels in the brain of 5XFAD mice. (A,C) CX43 mRNA levels drop significantly at all ages of 5XFAD mice compared to WT controls in both cortex and thalamus. (B,D) However, quantification of immunoblots showed increased protein levels of Cx43 in 3- and 9-months-old 5XFAD mice compared to their WT controls, respectively. (E,G) CX30 mRNA levels were similar at all ages of 5XFAD mice compared to WT controls in the cortex, except in thalamus where a significant drop was shown. (F,H) The quantification of immunoblots showed similar levels of $\mathrm{Cx30}$ protein in both brain areas. The asterisks inside the columns of mRNA graphs indicate the $p$-values representing significance of connexin levels in 5XFAD compared to WT controls, while the asterisks outside the columns represent the significance of connexin levels between different age groups of 5XFAD mice. The statistical analysis for mRNA was performed by one-way ANOVA followed by Kruskal-Wallis multiple comparisons test [5XFAD mice/age $(n=6)$, WT mice/age $(n=6)]$, while the immunoblot analysis was performed by unpaired $t$-test [5XFAD mice/age $(n=3)$, WT mice/age $(n=3)$ ]. Graphs show the mean and error bars indicate the standard error of the mean (SEM). Significance is given as: ${ }^{\star} p=0.0332,{ }^{\star \star} p=0.0021,{ }^{\star \star *} p=0.0002,{ }^{\star \star \star *} p<0.0001$.

significant difference compared to their WT controls, except in the thalamus, where 9-months-old 5XFAD mice showed significantly lower levels of Cx30 mRNA compared to the WT mice (Figures 5E,G). Furthermore, immunoblot analysis of Cx30 protein showed similar levels between all ages of 5XFAD mice compared to the WT controls (Figures $\mathbf{5 F}, \mathbf{H}$ and Supplementary Figure 3; shows original gels), in line with the mRNA levels. 
Generally, mRNA and immunoblot experiments were performed in lysed cortices and thalami, where the average levels of $\mathrm{Cx} 43$ and $\mathrm{Cx} 30$ were measured in the whole tissue and not specifically around the perimeter of $A \beta$ plaques, which were specifically measured in the immunostainings. Immunoblot results confirmed that $\mathrm{Cx} 43$ is the astrocytic $\mathrm{Cx}$ that is mostly altered in the context of 5XFAD brain pathology compared to WT mice, as observed by the immunofluorescence experiments as well. Whether $\mathrm{Cx} 43$ localization around $\mathrm{A} \beta$ plaques is only a consequence of astrogliosis or whether it also contributes to the disease propagation remains to be shown.

\section{Decreased Immunoreactivity of Cx47 in 5XFAD Mice}

Since we found an increased immunoreactivity of $\mathrm{Cx} 43$ around $\mathrm{A} \beta$ plaques in 9-months-old 5XFAD mice, we further asked whether the major partner of $\mathrm{Cx} 43$ at A/O heterotypic GJs, $\mathrm{Cx} 47$ (Orthmann-Murphy et al., 2007), would be affected in the course of AD pathology.

Double immunostainings were performed for $\mathrm{Cx} 47$ and either $A \beta$ or CC1 (oligodendrocyte marker) in 3- and 9months-old 5XFAD and control mice. We captured $\mathrm{Cx} 47$ immunoreactive oligodendrocytes in the presence of $A \beta$ in the RSP, MOp and MOs areas of cortical layer $\mathrm{V}$ and in the PO and VPM nucleus of the thalamus, with some being closer to $A \beta$ plaque microenvironment and some far away. All $\mathrm{Cx} 47$-positive puncta were used to measure the fluorescence intensity of $\mathrm{Cx} 47$ (Figure 6A). Cx47-positive GJ plaques were mostly localized around CC1-positive cell bodies and processes of mature oligodendrocytes (Figure 6B). These two immunostaining experiments ( $\mathrm{CC} 1 / \mathrm{Cx} 47, \mathrm{~A} \beta / \mathrm{Cx} 47)$ showed a decreased $\mathrm{Cx} 47$ fluorescence intensity in oligodendrocytes of 3- and 9-months-old 5XFAD mice compared to their WT age-matched controls. Quantification of $\mathrm{Cx} 47$ fluorescence intensity (Figures 6C,D) also confirmed that 5XFAD mice at both age groups showed decreased $\mathrm{Cx} 47$ immunoreactivity compared to their age-matched controls in the cortex and thalamus (cortex: 3M 5XFAD mice: 45,565 $\pm 2,032$ a.u., $3 \mathrm{M}$ WT mice: $54,811 \pm 3,066$ a.u.,9M 5XFAD mice: $45,600 \pm 4,727$ a.u., $9 \mathrm{M}$ WT mice: $66,579 \pm 5,692$ a.u.; thalamus: $3 \mathrm{M}$ 5XFAD mice: $27,974 \pm 1,235$ a.u., $3 \mathrm{M}$ WT mice: $41,482 \pm 4,191$ a.u., 9M 5XFAD mice: 34,966 $\pm 1,975$ a.u., 9M WT mice: $50,363 \pm 5,543$ a.u.). Thus, in contrast to the astrocyte partner $\mathrm{Cx} 43$, oligodendrocytic $\mathrm{Cx} 47$ shows reduced expression around $\mathrm{A} \beta$ plaques, indicating loss of $\mathrm{A} / \mathrm{O}$ connectivity in the context of $\mathrm{AD}$ pathology. Double immunostaining for $\mathrm{Cx} 47$ and $\mathrm{Cx} 43$ confirmed this finding by showing reduced $\mathrm{Cx} 47 \mathrm{GJ}$ plaques with less colocalization with $\mathrm{Cx} 43$ plaques in 9-months-old 5XFAD mice compared to WT mice (Supplementary Figure 4). Interestingly, Cx47 and Cx32 mRNA levels showed no significant difference between 5XFAD and WT mice in both the cortex and thalamus at all ages (Supplementary Figure 5). Also, double immunostaining for $\mathrm{A} \beta$ and $\mathrm{Cx} 32$ showed a diffuse immunoreactivity of $\mathrm{Cx} 32$ which was reduced in 5XFAD mice as well as disruption of $\mathrm{Cx} 32$ within and outside $\mathrm{A} \beta$ plaques (Supplementary Figure 6).

\section{Decreased Numbers of Oligodendrocyte Precursors and Mature Oligodendrocytes and Myelin Defects in 5XFAD Mice}

Furthermore, we analyzed cells of the oligodendrocyte lineage (excluding some $\mathrm{NG}^{+}$cells) in the cortex and thalamus of 3- and 9-months-old 5XFAD mice and their age-matched WT littermates, to investigate the reaction of these cells in the presence of $\mathrm{A} \beta$.

Double immunostaining was performed for Olig2, a marker of both oligodendrocyte precursors (OPCs) and mature oligodendrocytes, and CC1, a marker of mature oligodendrocytes. Three different populations of oligodendrocytes were observed; Olig2 ${ }^{+} / \mathrm{CC}^{+}$and Olig2 ${ }^{-} / \mathrm{CC}^{+}$cells, which indicate mature oligodendrocytes, and Olig2 ${ }^{+} / \mathrm{CC}^{-}$cells, which indicate OPCs (Figure 7A). Cells were counted from an area of $346 \mathrm{~mm}^{2}$. Olig2 ${ }^{+}$cells were not found to be in clusters around $A \beta$ plaques (Supplementary Figure 7). The mean numbers of OPC and mature oligodendrocyte populations were decreased at both ages of 5XFAD compared to control mice, in the cortex and thalamus (Figures 7B-E). These results reveal the loss of mature oligodendrocytes, together with the loss of Cx47 in 5XFAD mice. Therefore, the loss of A/O connectivity could affect the survival of mature oligodendrocytes. Moreover, the loss of OPCs clearly indicates that these cells were impaired due to $\mathrm{AD}$ pathology and possibly could not generate adequate numbers of mature oligodendrocytes at least at the level of WT mice.

We further looked myelination at the microenvironment of $\mathrm{A} \beta$ plaques by performing $\mathrm{A} \beta / \mathrm{PLP}$ double immunostaining in 9months-old 5XFAD and WT mice. Myelin proteolipid protein (PLP) is a major component of the CNS myelin (Yool et al., 2000). We observed myelin defects in areas surrounding $A \beta$ plaques in the cortex, corpus callosum and thalamus (Figure 8), which appears to be a consequence of OPCs and mature oligodendrocytes loss.

\section{DISCUSSION}

In this study we suggest the implication of glial Cxs in the progression of $\mathrm{AD}$. The increased $\mathrm{Cx} 43$ immunoreactivity at the microenvironment of $\mathrm{A} \beta$ plaques, reflects astrogliosis, while the reduced $\mathrm{Cx} 47$ immunoreactivity indicates loss of connection between astrocytes and oligodendrocytes. Moreover, we suggest that the disruption of O/A GJs could be a cause for the depletion of OPCs and mature oligodendrocytes in the 5XFAD mouse model of $\mathrm{AD}$. The disruption of the pan-glial syncytium together with astrogliosis could favor A/A connectivity and/or the shift of $\mathrm{Cx} 43$ GJs into HCs, with deleterious consequences in neuronal homeostasis.

The 5XFAD transgenic mouse model is an excellent model for the investigation of familial AD. It combines three mutations in the APP and two mutations in the PSEN1 gene to ensure rapid development of $A \beta$ plaques and especially an increase of $\mathrm{A} \beta_{42}$ in the cerebrum (Oakley et al., 2006). Therefore, this model 
A

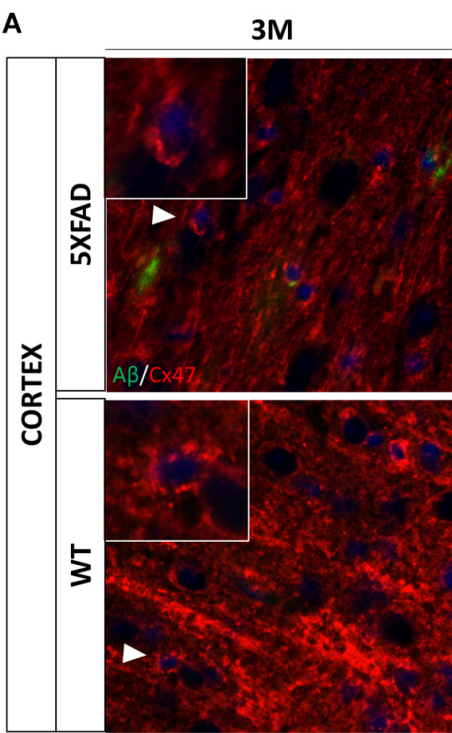

B

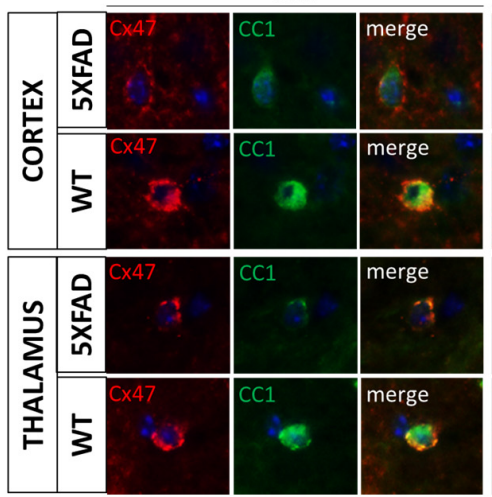

$9 M$

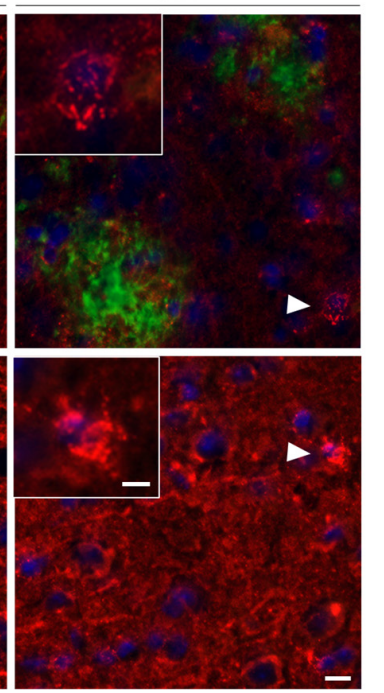

$3 \mathrm{M}$

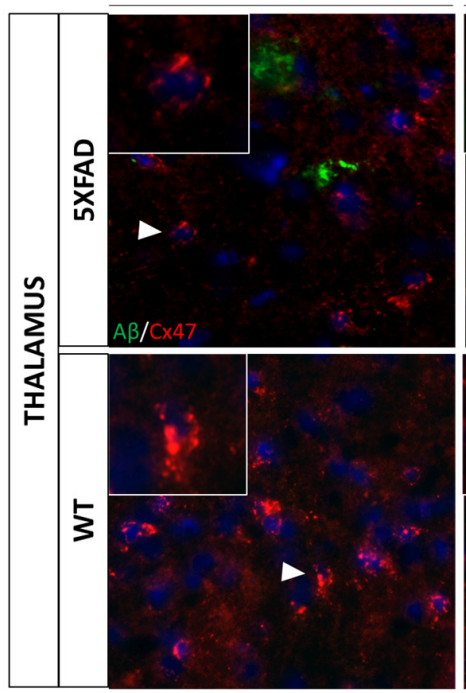

$9 \mathrm{M}$

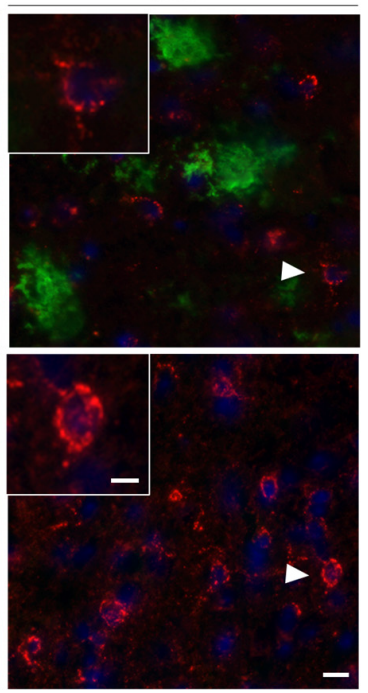

9M
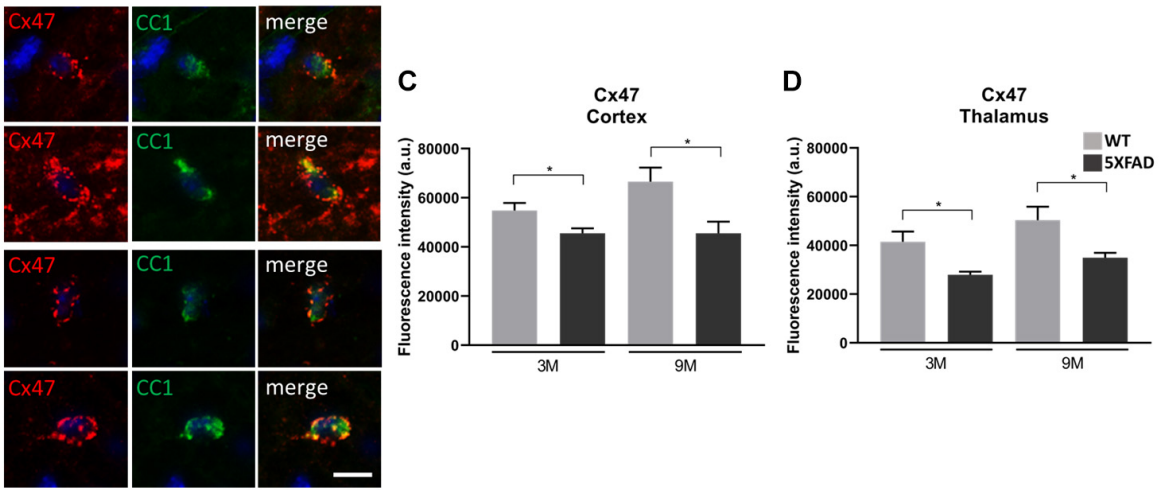

FIGURE 6 | Decreased immunoreactivity of CX47 in RSP, Mop, and MOs areas of cortical layer V and in the PO and VPM nucleus of the thalamus in 3- and 9-months-old 5XFAD mice. (A) Double immunostaining for AB/CX47 in cortical and thalamic areas showed decreased Cx47 immunoreactivity of 5XFAD mice in both ages compared to WT mice. Zoomed images show the Cx47 puncta in more detail. (B) Double immunostaining for CC1/Cx47 in cortical and thalamic areas in the presence of A $\beta$ plaques, in 5XFAD and WT mice. Cx47-positive GJ plaques were expressed by mature oligodendrocytes. Cell nuclei were counterstained with DAPI (blue). (C,D) Quantification of Cx47 fluorescence intensity confirmed a decreased immunoreactivity as observed in the immunostainings. The statistical analysis was performed by unpaired $t$-test [5XFAD mice/age $(n=6)$, WT mice/age $(n=6)]$. Graphs show the mean and error bars indicate the standard error of the mean (SEM). Significance is given as: ${ }^{*} p=0.0332$. Scale bars $=10 \mu \mathrm{m}$ in $(\mathbf{A}, \mathbf{B}) ; 5 \mu \mathrm{m}$ in higher magnification insets.

provides an advantage for studying AD pathology over other $\mathrm{AD}$ mouse models which develop $\mathrm{A} \beta$ deposition at a slower rate (Games et al., 1995; Hsiao et al., 1996; Sturchler-Pierrat et al., 1997; Jankowsky et al., 2004; Radde et al., 2006). However, this model is characterized by the absence of neurofibrillary tangles, thus the disease pathology is partially represented, which can be a drawback in understanding the disease mechanisms. The development of both $\mathrm{A} \beta$ and tau pathology in $\mathrm{AD}$ models depicts their interplay during the development and progression of the disease, thus demonstrating the $\mathrm{AD}$ phenotypic alterations in a more comprehensive way (Lewis et al., 2001; Oddo et al., 2003; Boutajangout et al., 2004; Bolmont et al., 2007).

Extracellular $A \beta$ plaques appear at around 2 months of age in 5XFAD mice (Oakley et al., 2006). Plaques are initially found in the cortex and then spread into other brain areas, as deposition rapidly increases with age (Maarouf et al., 2013), which we confirmed in this study. Neuronal loss has also been observed at 6 months of age in cortical layer V (Oakley et al., 2006; Eimer and Vassar, 2013). We confirmed loss of mature neurons starting at 6 and continuing at 9 months of age in cortical layer $\mathrm{V}$, an area with the heaviest deposition and largest size of $\mathrm{A} \beta$ plaques compared to other cortical regions. We showed that 5XFAD mice exhibited cognitive deficits compared to WT mice at the age of 6 and 9 months as shown by the T-maze behavioral test, possibly indicating that neuronal loss at those ages causes memory deficits. Spatial memory impairment was also observed by others at 4, 5, and 6 months of age (Oakley et al., 2006; Ohno et al., 2006; Devi and Ohno, 2010; Jawhar et al., 2012; Xiao et al., 2015). Furthermore, in 5XFAD mice, gliosis also appears early in the brain and progresses with age due to 

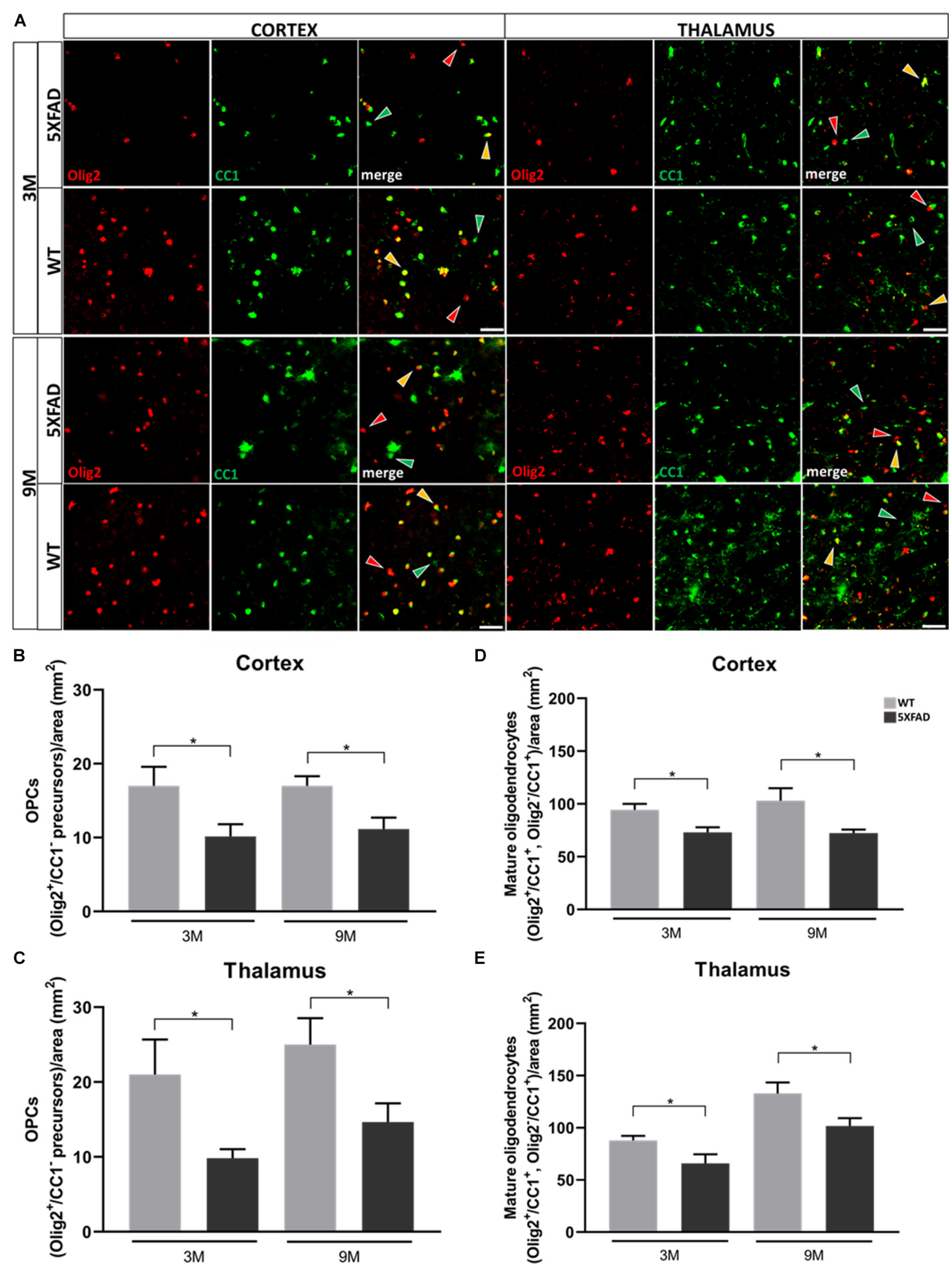

FIGURE 7 | Depletion of OPC and mature oligodendrocyte numbers in 3- and 9-months-old in 5XFAD mice. (A) Double immunostaining for Olig2/CC1 in cortical and thalamic areas of 5XFAD and WT mice. Yellow, green and red arrows depict Olig2 ${ }^{+} / \mathrm{CC} 1^{+}$mature oligodendrocytes, Olig2 ${ }^{-} / \mathrm{CC} 1^{+}$mature oligodendrocytes and Olig2 ${ }^{+} / \mathrm{CC} 1^{-}$OPCs, respectively. (B) Mean numbers of OPCs in the cortex and thalamus (C). (D) Total mean numbers of mature oligodendrocytes (Olig2 ${ }^{+} / \mathrm{CC} 1^{+}$, Olig2 ${ }^{-} / \mathrm{CC} 1^{+}$cells) in the cortex and thalamus (E). The statistical analysis was performed by unpaired $t$-test [5XFAD mice/age $(n=6)$, WT mice/age $\left.(n=6)\right]$. Graphs show the mean and error bars indicate the standard error of the mean (SEM). Significance is given as: ${ }^{*} p=0.0332$. Scale bar $=50 \mu \mathrm{m}$. 


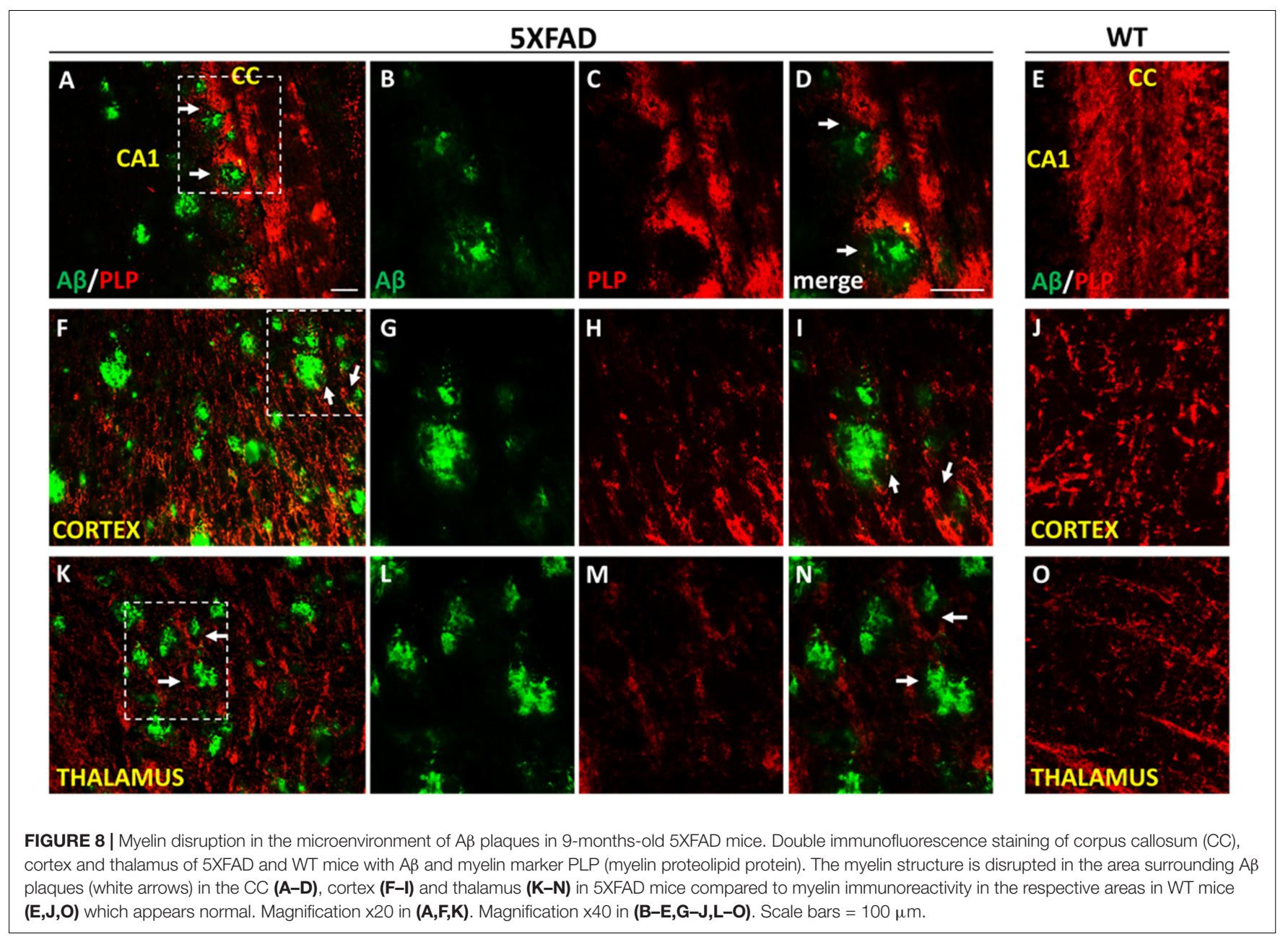

the early and aggressive amyloid deposition, as we observed in our experiments. We observed proliferation of reactive $\mathrm{GFAP}^{+}$ astrocytes and activated $\mathrm{Iba1}^{+}$microglia from 3 to 9 months of age, which is in parallel with the amyloid load profile in each age. Reactive astrocytes and microglia surround $\mathrm{A} \beta$ plaques inducing inflammation, in human and rodent brains with the AD pathology (Nagy et al., 1996; Sturchler-Pierrat et al., 1997; Oakley et al., 2006).

We demonstrate here that astrocytic Cxs (Cx43 and Cx30) and especially $\mathrm{Cx} 43$, show increased immunoreactivity around the perimeter of $A \beta$ plaques in the cortex and thalamus of older 5XFAD mice. This resonates to the fact that in older mice, $\mathrm{A} \beta$ plaques are larger, the inflammatory response is higher and generally the pathology is more severe. This finding is in concordance with other studies, previously performed in postmortem human samples and mouse models of AD (Nagy et al., 1996; Mei et al., 2010). Moreover, our immunoblot analysis demonstrated that the total $\mathrm{Cx} 43$ protein levels increased at both ages in 5XFAD mice compared to their controls. The increased protein levels of $\mathrm{Cx} 43$ together with the immunostaining results clearly confirmed the increased $\mathrm{Cx} 43$ expression at the microenvironment of $A \beta$ plaques in older ages, in association with disease progression. Likewise, Cx30 was also increased within the $\mathrm{A} \beta$ plaque microenvironment in older mice but immunoblot results showed no difference in $\mathrm{Cx} 30$ protein levels at both ages compared to their controls. This may be related to the fact that $\mathrm{Cx} 30$ is the dominant $\mathrm{Cx}$ isoform and more diffusely expressed in gray matter astrocytes (Griemsmann et al., 2015). These results indicate that $\mathrm{Cx} 43$ is more strongly associated with progression of $\mathrm{AD}$ than $\mathrm{Cx} 30$. Furthermore, when $\mathrm{Cx} 43$ was analyzed at the transcriptional level, it was surprisingly downregulated at all ages in 5XFAD mice, while protein levels were increased as mentioned previously. This might be due to transcriptional modifications that hinder the transcription process. The downregulation of $\mathrm{Cx} 43$ gene expression might be due to inflammatory mediators. It was reported that the activation of the JNK pathway through TNF- $\alpha$, reduced Cx43 gene promoter activation (Yan et al., 2018). Also, the presence of microglia and their interaction with astrocytes in an inflammatory environment, like $\mathrm{AD}$, could contribute to the downregulation of $\mathrm{Cx} 43$ gene. Reduction of astrocytic Cx43 mRNA levels occurred after treating astrocyte/microglia cocultures but not astrocyte-rich cultures, with interferon (IFN) $\gamma$ or IL-17, implying that microglia were responsible for this reduction. The authors depicted an IFN $\gamma$-mediated microglial release of IL-1 $\beta$ as the causal mechanism (Watanabe et al., 2016). 
Furthermore, JNK and NF- $\mathrm{kB}$ pathways were activated via IL-1 $\beta$ in astrocytes (Wu et al., 2004), therefore the reduction in $\mathrm{Cx} 43$ mRNA could be caused through those pathways.

Moreover, due to the activation of astrocytes in a neuroinflammatory environment, $\mathrm{Cx} 43$ might shift its expression from GJs to HCs (Retamal et al., 2007; Kielian, 2008). The combination of TNF-a and IL- $1 \beta$ in astrocyte cultures of mice, caused the reduction of GJs and the upregulation of $\mathrm{Cx} 43 \mathrm{HC}$ activity (Chen et al., 2014; Xu et al., 2019). Prolonged activation of $\mathrm{Cx} 43 \mathrm{HCs}$ in the presence of $\mathrm{A} \beta$ plaques, was reported in astrocytes of APP/PS1 mice and especially those near plaques (Yi et al., 2016). Our results could indicate a pathological pathway in the 5XFAD mouse model of $\mathrm{AD}$, involving the opening of $\mathrm{Cx} 43$ HCs, but this requires further investigation. Activated microglia can release pro-inflammatory cytokines, which increase astrocytic Cx43 HC opening (Orellana et al., 2009). Increase in $\left[\mathrm{Ca}^{2+}\right]_{\mathrm{i}}$ could trigger the openings of $\mathrm{Cx} 43 \mathrm{HCs}$, allowing $\mathrm{Ca}^{2+}$ entrance, thus establishing the maintenance of upregulated $\left[\mathrm{Ca}^{2+}\right]_{\mathrm{i}}$ in astrocytes. Then, release of gliotransmitters occurs via HCs leading to increased extracellular glutamate and ATP (Orellana et al., 2011b). In the presence of $A \beta$, glutamate binds to neuronal NMDA receptors and ATP to purinergic (P2X) receptors, which generate the enhancement of intraneuronal $\mathrm{Ca}^{+2}$, causing neuronal dysfunction and synaptic loss (Talantova et al., 2013), neuritic alterations (Kuchibhotla et al., 2008), and oxidative stress (Lin and Beal, 2006). ATP also stimulates the activation of $\mathrm{P} 2 \times 7$ receptors in astrocytes and microglia triggering the release of IL- $1 \beta$ which is toxic to neurons (Pelegrin and Surprenant, 2009). Finally, glutamate and ATP trigger the opening of neuronal Panx1 HCs (Pelegrin and Surprenant, 2006), which allow further $\mathrm{Ca}^{2+}$ entry causing neuronal death and activation of neurotoxic cascades (Orellana et al., 2011a).

Furthermore, we showed that $\mathrm{Cx} 47$ immunoreactivity was reduced in mature oligodendrocytes in the presence of $A \beta$, while $\mathrm{Cx} 43$ immunoreactivity was increased around $A \beta$ plaques. We also confirmed this finding by showing reduced colocalization of $\mathrm{Cx} 47$ with $\mathrm{Cx} 43 \mathrm{GJ}$ plaques (Supplementary Figure 4). Such findings were also observed in chronic MS lesions in both white and gray matter. In particular, $\mathrm{Cx} 43 \mathrm{GJ}$ plaques showed increased density but $\mathrm{Cx} 47 \mathrm{GJ}$ plaques were decreased in numbers, while there was a decreased colocalization of $\mathrm{Cx} 47$ and $\mathrm{Cx} 43$ in the MS normal appearing white matter and in periplaque areas (Markoullis et al., 2012b, 2014). Loss of Cx47 is observed not only in MS (Masaki et al., 2013) but also in other neuroinflammatory disorders including Neuromyelitis optica and Balo's disease, an MS variant (Masaki et al., 2012) as a result of astrogliosis, which compromises $\mathrm{Cx} 47$.

These findings indicate a possible mechanism for the spreading of the demyelinating disease, which is the disruption of the O/A GJs caused by impairment of the pan-glial GJ network disturbing primarily the oligodendrocytes, which possibly occurs in $\mathrm{AD}$ as well. These contrasting patterns of $\mathrm{Cx} 47$ and $\mathrm{Cx} 43$ were also observed in a chronic EAE mouse model of MS, showing that astrocytes are the major determinants for spreading GJ pathology (Markoullis et al., 2012a). Upregulation of Cx43 was also observed in other chronic stage EAE models (Roscoe et al., 2007a,b), in a mouse model of Parnkinson's disease
(Rufer et al., 1996) and in epilepsy in humans (Aronica et al., 2001; Fonseca et al., 2002). Also, increased Cx43 and reduced $\mathrm{Cx} 47$ immunoreactivity were observed at the progressive and end stages of an amyotrophic lateral sclerosis mouse model (Cui et al., 2014). We suggest that in the 5XFAD mouse model of $\mathrm{AD}$, the increase of $\mathrm{Cx} 43$ but not $\mathrm{Cx} 47$ immunoreactivity could possibly indicate the presence of $\mathrm{Cx} 43$ in $\mathrm{A} / \mathrm{A}$ and not in $\mathrm{O} / \mathrm{A}$ channels, leading to demyelination, just like in chronic EAE and MS (Markoullis et al., 2012a).

The loss of A/O connectivity could also affect the survival of mature oligodendrocytes in 5XFAD mice, which were found to be depleted in our study. Loss of O/A GJs formed by Cx47 and $\mathrm{Cx} 43$, may reflect the dependency of $\mathrm{Cx} 47$ expression on the presence of $\mathrm{Cx} 43$ on the cell membrane (May et al., 2013). The loss of O/A GJs is predicted to negatively affect the survival and function of oligodendrocytes. The significance of $\mathrm{O} / \mathrm{A}$ connections is highlighted by the fact that $\mathrm{Cx} 43$ mutations which dissociate A/O GJs, also induce demyelination (Paznekas et al., 2003). Severe demyelination is also caused in $\mathrm{Cx} 43 / \mathrm{Cx} 30$ double $\mathrm{KO}$ mice which depict disruption of O/A GJs (Lutz et al., 2009). AD models show different alterations in myelination patterns and oligodendrocyte capacity, prior to the appearance of $\mathrm{A} \beta$ plaques depending on the different mutations they carry (Desai et al., 2009, 2010; Cai and Xiao, 2016). OPCs and oligodendrocytes are the most vulnerable cells of the CNS due to the complexity of their differentiation mechanism and their metabolic program (Papaneophytou et al., 2019). Indeed, the loss of OPCs in 5XFAD mice indicates that these cells become vulnerable in the disease course and possibly cannot generate new populations of myelinating oligodendrocytes to compensate for the depletion of mature oligodendrocytes observed in this model. It is possible that the repair of damaged OPCs could not be achieved, thus mature oligodendrocytes could not be generated, causing myelin breakdown (Roher et al., 2002; Sjöbeck et al., 2005). Increased differentiation of OPCs into mature oligodendrocytes was reported in the early stages of $\mathrm{AD}$, as a compensatory mechanism for myelin loss (Behrendt et al., 2013). However, we did not observe this in 3-months-old 5XFAD mice. This could possibly occur in an earlier stage, but this requires further investigation. Also, the demyelination and remyelination processes have not been studied extensively in the 5XFAD model and thus require further thorough examination. Myelin basic protein (MBP) was found to be significantly reduced in 1-month-old 5XFAD compared to WT mice, indicating myelin loss as an early event (Wu et al., 2018). Also, 12-months-old 5XFAD mice exhibited disruption of myelin focally around $\mathrm{A} \beta$ plaques on the edge of corpus callosum (Kaya et al., 2020). We also observed myelin defects at the microenvironment of $\mathrm{A} \beta$ plaques in 9-months-old 5XFAD mice, which explains the decrease in the numbers of oligodendrocytes. Direct $\mathrm{A} \beta$ toxic effects (Lee et al., 2004; Desai et al., 2010; Agosta et al., 2014) and $A \beta$ oligomer toxicity are mechanisms that influence proliferation, survival, and function of OPCs and oligodendrocytes, causing white matter degeneration and impaired myelin maintenance and remyelination (Horiuchi et al., 2012). Moreover, inflammatory signals exacerbate 
$\mathrm{A} \beta$-induced demyelination and oligodendrocyte damage (Jantaratnotai et al., 2003).

\section{CONCLUSION}

Our study reports the increased $\mathrm{Cx} 43$ immunoreactivity in the immediate vicinity of $\mathrm{A} \beta$ plaques, for the first time in the 5XFAD mouse model of $\mathrm{AD}$. It also provides evidence of decreased $\mathrm{Cx} 47$ and $\mathrm{Cx} 32$ immunoreactivity suggesting a reduction in $\mathrm{Cx} 43$ Cx47 GJs, indicating the loss of A/O coupling. The loss of interaction between astrocytes and oligodendrocytes as well as $\mathrm{A} \beta$ pathology could be factors that induce loss of OPCs and mature oligodendrocytes with myelin defects as well in this model. The disruption of glial syncytium and astrogliosis favors A/A coupling and possibly the activation of $\mathrm{Cx} 43 \mathrm{HCs}$, with detrimental effects in neuronal survival. All these provide evidence that glial Cxs might contribute to the progression of $\mathrm{AD}$. These results warrant further study of oligodendrocyte $\mathrm{Cxs}$ in $\mathrm{AD}$ pathophysiology and progression.

\section{DATA AVAILABILITY STATEMENT}

All datasets presented in this study are included in the article/Supplementary Material.

\section{ETHICS STATEMENT}

The animal study was reviewed and approved by the Cyprus Government's Veterinary Services 1417 Nicosia, Cyprus.

\section{AUTHOR CONTRIBUTIONS}

SA designed and performed the experiments, analyzed and interpreted data, and wrote the manuscript. IK performed

\section{REFERENCES}

Agosta, F., Libera, D. D., Spinelli, E. G., Finardi, A., Canu, E., Bergami, A., et al. (2014). Myeloid microvesicles in cerebrospinal fluid are associated with myelin damage and neuronal loss in mild cognitive impairment and alzheimer disease. Ann. Neurol. 76, 813-825. doi: 10.1002/ana.24235

Aronica, E., Gorter, J. A., Jansen, G. H., Leenstra, S., Yankaya, B., and Troost, D. (2001). Expression of connexin 43 and connexin 32 gap-junction proteins in epilepsy-associated brain tumors and in the perilesional epileptic cortex. Acta Neuropathol. 101, 449-459. doi: 10.1007/s004010000305

Balez, R., and Ooi, L. (2016). Getting to NO Alzheimer's disease: neuroprotection versus neurotoxicity mediated by nitric oxide. Oxid. Med. Cell. Longev. 2016:3806157. doi: 10.1155/2016/3806157

Bautista, W., McCrea, D. A., and Nagy, J. I. (2014). Connexin36 identified at morphologically mixed chemical/electrical synapses on trigeminal motoneurons and at primary afferent terminals on spinal cord neurons in adult mouse and rat. Neuroscience 263, 159-180. doi: 10.1016/j.neuroscience.2013.12.057

Behrendt, G., Baer, K., Buffo, A., Curtis, M. A., Faull, R. L., Rees, M. I., et al. (2013). Dynamic changes in myelin aberrations and oligodendrocyte generation in chronic amyloidosis in mice and men. Glia 61, 273-286. doi: 10.1002/glia.22432 experiments, supervised the study, and reviewed the manuscript. MS assisted with data analysis and interpretation. IS and EG provided protocols and guided with experimental procedures. SP supervised the study and reviewed the manuscript. KK contributed to conception, study design and had critical input in the preparation and review of the manuscript. All authors contributed to the article and approved the submitted version.

\section{FUNDING}

This work was supported by the Cyprus School of Molecular Medicine of the Cyprus Institute of Neurology and Genetics.

\section{ACKNOWLEDGMENTS}

We would like to thank Dr. Petros Petrou (Department of Biochemical Genetics, The Cyprus Institute of Neurology and Genetics, Cyprus) for his assistance with BCA protein assay and also Dr. Andreas Hadjisavvas (Electron Microscopy and Molecular Pathology Department, The Cyprus Institute of Neurology and Genetics, Cyprus) for providing equipment. Also, we would like to acknowledge Drs. Melina Christou and Neoklis Makrides for helpful conversations. The antibody against tubulin-E7 (developed by Michael Klymkowsky) was obtained from the Developmental Studies Hybridoma Bank created by the National Institute of Child Health and Human Development of the NIH and maintained at The University of Iowa, Department of Biology, Iowa City, IA 52242.

\section{SUPPLEMENTARY MATERIAL}

The Supplementary Material for this article can be found online at: https://www.frontiersin.org/articles/10.3389/fnins. 2020.582934/full\#supplementary-material

Belousov, A. B., Nishimune, H., Denisova, J. V., and Fontes, J. D. (2018). A potential role for neuronal connexin 36 in the pathogenesis of amyotrophic lateral sclerosis. Neurosci. Lett. 666, 1-4. doi: 10.1016/j.neulet.2017.12.027

Bolmont, T., Clavaguera, F., Meyer-Luehmann, M., Herzig, M. C., Radde, R., Staufenbiel, M., et al. (2007). Induction of tau pathology by intracerebral infusion of amyloid- $\beta$-containing brain extract and by amyloid- $\beta$ deposition in APP x tau transgenic mice. Am. J. Pathol. 171, 2012-2020. doi: 10.2353/ajpath. 2007.070403

Boutajangout, A., Authelet, M., Blanchard, V., Touchet, N., Tremp, G., Pradier, L., et al. (2004). Characterisation of cytoskeletal abnormalities in mice transgenic for wild-type human tau and familial Alzheimer's disease mutants of APP and presenilin-1. Neurobiol. Dis. 15, 47-60. doi: 10.1016/j.nbd.2003. 09.007

Brand-Schieber, E., Werner, P., Iacobas, D. A., Iacobas, S., Beelitz, M., Lowery, S. L., et al. (2005). Connexin43, the major gap junction protein of astrocytes, is downregulated in inflamed white matter in an animal model of multiple sclerosis. J. Neurosci. Res. 80, 798-808. doi: 10.1002/jnr.20474

Cai, Z., and Xiao, M. (2016). Oligodendrocytes and Alzheimer's disease. Int. J. Neurosci. 126, 97-104. doi: 10.3109/00207454.2015.1025778

Chen, G., Park, C. K., Xie, R. G., Berta, T., Nedergaard, M., and Ji, R. R. (2014). Connexin-43 induces chemokine release from spinal cord astrocytes 
to maintain late-phase neuropathic pain in mice. Brain 137, 2193-2209. doi: 10.1093/brain/awu140

Cragnolini, A., Lampitella, G., Virtuoso, A., Viscovo, I., Panetsos, F., Papa, M., et al. (2020). Regional brain susceptibility to neurodegeneration: What is the role of glial cells? Neural Regen. Res. 15, 838-842. doi: 10.4103/1673-5374.268897

Cruz, N. F., Ball, K. K., and Dienel, G. A. (2010). Astrocytic gap junctional communication is reduced in amyloid- $\beta$-treated cultured astrocytes, but not in Alzheimer's disease transgenic mice. ASN Neuro 2:e00041. doi: 10.1042/ AN20100017

Cui, Y., Masaki, K., Yamasaki, R., Imamura, S., Suzuki, S. O., Hayashi, S., et al. (2014). Extensive dysregulations of oligodendrocytic and astrocytic connexins are associated with disease progression in an amyotrophic lateral sclerosis mouse model. J. Neuroinflammation 11:42. doi: 10.1186/1742-2094-11-42

Deacon, R. M. J., and Rawlins, J. N. P. (2006). T-maze alternation in the rodent. Nat. Protoc. 1, 7-12. doi: 10.1038/nprot.2006.2

Delekate, A., Füchtemeier, M., Schumacher, T., Ulbrich, C., Foddis, M., and Petzold, G. C. (2014). Metabotropic P2Y1 receptor signalling mediates astrocytic hyperactivity in vivo in an Alzheimer's disease mouse model. Nat. Commun. 5:5422. doi: 10.1038/ncomms6422

Desai, M. K., Mastrangelo, M. A., Ryan, D. A., Sudol, K. L., Narrow, W. C., and Bowers, W. J. (2010). Early oligodendrocyte/myelin pathology in Alzheimer's disease mice constitutes a novel therapeutic target. Am. J. Pathol. 177, 14221435. doi: 10.2353/ajpath.2010.100087

Desai, M. K., Sudol, K. L., Janelsins, M. C., Mastrangelo, M. A., Frazer, M. E., and Bowers, W. J. (2009). Triple-transgenic Alzheimer's disease mice exhibit region-specific abnormalities in brain myelination patterns prior to appearance of amyloid and tau pathology. Glia 177, 1422-1435. doi: 10.1002/glia.20734

Devi, L., and Ohno, M. (2010). Phospho-eIF2 $\alpha$ level is important for determining abilities of BACE1 reduction to rescue cholinergic neurodegeneration and memory defects in 5XFAD mice. PLoS One 5:e12974. doi: 10.1371/journal.pone. 0012974

Eimer, W. A., and Vassar, R. (2013). Neuron loss in the 5XFAD mouse model of Alzheimer's disease correlates with intraneuronal A $\beta 42$ accumulation and Caspase-3 activation. Mol. Neurodegener. 8:2. doi: 10.1186/1750-1326-8-2

Eugenin, E. A., Basilio, D., Sáez, J. C., Orellana, J. A., Raine, C. S., Bukauskas, F., et al. (2012). The role of gap junction channels during physiologic and pathologic conditions of the human central nervous system. J. Neuroimmune Pharmacol. 7, 499-518. doi: 10.1007/s11481-012-9352-5

Fakhoury, M. (2017). Microglia and astrocytes in Alzheimer's disease: implications for therapy. Curr. Neuropharmacol. 16, 508-518. doi: 10.2174/1570159x15666170720095240

Fonseca, C. G., Green, C. R., and Nicholson, L. F. B. (2002). Upregulation in astrocytic connexin 43 gap junction levels may exacerbate generalized seizures in mesial temporal lobe epilepsy. Brain Res. 929, 105-116. doi: 10.1016/S00068993(01)03289-9

Games, D., Adams, D., Alessandrini, R., Barbour, R., Borthelette, P., Blackwell, C., et al. (1995). Alzheimer-type neuropathology in transgenic mice overexpressing V717F $\beta$-amyloid precursor protein. Nature 523-527. doi: 10.1038/373523a0

Giaume, C., Koulakoff, A., Roux, L., Holcman, D., and Rouach, N. (2010). Astroglial networks: a step further in neuroglial and gliovascular interactions. Nat. Rev. Neurosci. 11, 87-99. doi: 10.1038/nrn2757

Griemsmann, S., Höft, S. P., Bedner, P., Zhang, J., Von Staden, E., Beinhauer, A., et al. (2015). Characterization of panglial gap junction networks in the thalamus, neocortex, and hippocampus reveals a unique population of glial cells. Cereb. Cortex 25, 3420-3433. doi: 10.1093/cercor/bhu157

Griñán-Ferré, C., Sarroca, S., Ivanova, A., Puigoriol-Illamola, D., Aguado, F., Camins, A., et al. (2016). Epigenetic mechanisms underlying cognitive impairment and Alzheimer disease hallmarks in 5XFAD mice. Aging 8, 664684. doi: 10.18632/aging.100906

Haass, C., and Selkoe, D. J. (2007). Soluble protein oligomers in neurodegeneration: lessons from the Alzheimer's amyloid $\beta$-peptide. Nat. Rev. Mol. Cell Biol. 8, 101-112. doi: 10.1038/nrm2101

Hardy, J., and Selkoe, D. J. (2002). The Amyloid Hypothesis of Alzheimer's Disease: progress and Problems on the Road to Therapeutics. Science 297, 353-357. doi: 10.1126/science. 1072994

Haughey, N. J., and Mattson, M. P. (2003). Alzheimer's amyloid $\beta$-peptide enhances ATP/Gap junction-mediated calcium-wave propagation in astrocytes. Neuromol. Med. 3, 173-180. doi: 10.1385/nmm:3:3:173
Horiuchi, M., Maezawa, I., Itoh, A., Wakayama, K., Jin, L. W., Itoh, T., et al. (2012). Amyloid $\beta 1-42$ oligomer inhibits myelin sheet formation in vitro. Neurobiol. Aging 33, 499-509. doi: 10.1016/j.neurobiolaging.2010.05.007

Hsiao, K., Chapman, P., Nilsen, S., Eckman, C., Harigaya, Y., Younkin, S., et al. (1996). Correlative memory deficits, $A \beta$ elevation, and amyloid plaques in transgenic mice. Science 50, 793-800. doi: 10.1126/science.274.5284.99

Jankowsky, J. L., Fadale, D. J., Anderson, J., Xu, G. M., Gonzales, V., Jenkins, N. A., et al. (2004). Mutant presenilins specifically elevate the levels of the 42 residue $\beta$ amyloid peptide in vivo: evidence for augmentation of a 42 -specific $\gamma$ secretase. Hum. Mol. Genet. 13, 159-170. doi: 10.1093/hmg/ddh019

Jantaratnotai, N., Ryu, J. K., Kim, S. U., and McLarnon, J. G. (2003). Amyloid $\beta$ peptide-induced corpus callosum damage and glial activation in vivo. Neuroreport 14, 1429-1433. doi: 10.1097/00001756-200308060-00005

Jawhar, S., Trawicka, A., Jenneckens, C., Bayer, T. A., and Wirths, O. (2012). Motor deficits, neuron loss, and reduced anxiety coinciding with axonal degeneration and intraneuronal $\mathrm{A} \beta$ aggregation in the 5XFAD mouse model of Alzheimer's disease. Neurobiol. Aging 33, 196.e29-196.e40. doi: 10.1016/j.neurobiolaging. 2010.05.027

Jeng, L. J. B., Balice-Gordon, R. J., Messing, A., Fischbeck, K. H., and Scherer, S. S. (2006). The effects of a dominant connexin 32 mutant in myelinating Schwann cells. Mol. Cell. Neurosci. 32, 283-298. doi: 10.1016/j.mcn.2006.05.001

Kamphuis, W., Middeldorp, J., Kooijman, L., Sluijs, J. A., Kooi, E. J., Moeton, M., et al. (2014). Glial fibrillary acidic protein isoform expression in plaque related astrogliosis in Alzheimer's disease. Neurobiol. Aging 35, 492-510. doi: 10.1016/j.neurobiolaging.2013.09.035

Kaya, I., Jennische, E., Lange, S., Tarik Baykal, A., Malmberg, P., and Fletcher, J. S. (2020). Brain region-specific amyloid plaque-associated myelin lipid loss, APOE deposition and disruption of the myelin sheath in familial Alzheimer's disease mice. J. Neurochem. 154, 7-10. doi: 10.1111/jnc.14999

Kielian, T. (2008). Glial connexins and gap junctions in CNS inflammation and disease. J. Neurochem. 106, 1000-1016. doi: 10.1111/j.1471-4159.2008.05405.x

Kleopa, K. A., Orthmann, J. L., Enriquez, A., Paul, D. L., and Scherer, S. S. (2004). Unique distributions of the gap junction proteins connexin29, connexin32, and connexin47 in oligodendrocytes. Glia 47, 346-357. doi: 10.1002/glia.20043

Kobayakawa, Y., Masaki, K., Yamasaki, R., Shiraishi, W., Hayashida, S., Hayashi, S., et al. (2018). Downregulation of neuronal and dendritic Connexin36-made electrical synapses without glutamatergic axon terminals in spinal anterior horn cells from the early stage of amyotrophic lateral sclerosis. Front. Neurosci. 12:894. doi: 10.3389/fnins.2018.00894

Koulakoff, A., Mei, X., Orellana, J. A., Sáez, J. C., and Giaume, C. (2012). Glial connexin expression and function in the context of Alzheimer's disease. Biochim. Biophys. Acta Biomembr. 1818, 2048-2057. doi: 10.1016/j.bbamem. 2011.10 .001

Kuchibhotla, K. V., Goldman, S. T., Lattarulo, C. R., Wu, H. Y., Hyman, B. T., and Bacskai, B. J. (2008). A $\beta$ plaques lead to aberrant regulation of calcium homeostasis in vivo resulting in structural and functional disruption of neuronal networks. Neuron 35, 492-510. doi: 10.1016/j.neuron.2008. 06.008

Lee, J. T., Xu, J., Lee, J. M., Ku, G., Han, X., Yang, D. I., et al. (2004). Amyloid- $\beta$ peptide induces oligodendrocyte death by activating the neutral sphingomyelinase-ceramide pathway. J. Cell Biol. 164, 123-131. doi: 10.1083/ jcb. 200307017

Lewis, J., Dickson, D. W., Lin, W. L., Chisholm, L., Corral, A., Jones, G., et al. (2001). Enhanced neurofibrillary degeneration in transgenic mice expressing mutant tau and APP. Science 293, 1487-1491. doi: 10.1126/science.1058189

Lin, M. T., and Beal, M. F. (2006). Mitochondrial dysfunction and oxidative stress in neurodegenerative diseases. Nature 443, 787-795. doi: 10.1038/nature05292

Lutz, S. E., Zhao, Y., Gulinello, M., Lee, S. C., Raine, C. S., and Brosnan, C. F. (2009). Deletion of astrocyte connexins 43 and 30 leads to a dysmyelinating phenotype and hippocampal CA1 vacuolation. J. Neurosci. 29, 7743-7752. doi: 10.1523/JNEUROSCI.0341-09.2009

Maarouf, C. L., Kokjohn, T. A., Whiteside, C. M., Macias, M. P., Kalback, W. M., Sabbagh, M. N., et al. (2013). Molecular Differences and Similarities between Alzheimer's Disease and the 5XFAD Transgenic Mouse Model of Amyloidosis. Biochem. Insights 6:bci-s13025. doi: 10.4137/bci.s13025

Magnotti, L. M., Goodenough, D. A., and Paul, D. L. (2011). Functional heterotypic interactions between astrocyte and oligodendrocyte connexins. Glia 59, 26-34 doi: $10.1002 /$ glia.21073 
Markoullis, K., Sargiannidou, I., Gardner, C., Hadjisavvas, A., Reynolds, R., and Kleopa, K. A. (2012a). Disruption of oligodendrocyte gap junctions in experimental autoimmune encephalomyelitis. Glia 60, 1053-1066. doi: 10.1002/ glia. 22334

Markoullis, K., Sargiannidou, I., Schiza, N., Hadjisavvas, A., Roncaroli, F., Reynolds, R., et al. (2012b). Gap junction pathology in multiple sclerosis lesions and normal-appearing white matter. Acta Neuropathol. 123, 873-886. doi: 10. 1007/s00401-012-0978-4

Markoullis, K., Sargiannidou, I., Schiza, N., Roncaroli, F., Reynolds, R., and Kleopa, K. A. (2014). Oligodendrocyte gap junction loss and disconnection from reactive astrocytes in multiple sclerosis gray matter. J. Neuropathol. Exp. Neurol. 73, 865-879. doi: 10.1097/NEN.0000000000000106

Masaki, K. (2013). Connexin pathology in acute multiple sclerosis, Baló's disease and neuromyelitis optica. Clin. Exp. Neuroimmunol. 4, 36-44. doi: 10.1111/ cen3.12062

Masaki, K., Suzuki, S. O., Matsushita, T., Matsuoka, T., Imamura, S., Yamasaki, R., et al. (2013). Connexin 43 astrocytopathy linked to rapidly progressive multiple sclerosis and neuromyelitis optica. PLoS One 8:e72919. doi: 10.1371/journal. pone.0072919

Masaki, K., Suzuki, S. O., Matsushita, T., Yonekawa, T., Matsuoka, T., Isobe, N., et al. (2012). Extensive loss of connexins in Baló's disease: evidence for an autoantibody-independent astrocytopathy via impaired astrocyte-oligodendrocyte/ myelin interaction. Acta Neuropathol. 123, 887-900. doi: 10.1007/s00401-0120972-x

May, D., Tress, O., Seifert, G., and Willecke, K. (2013). Connexin47 protein phosphorylation and stability in oligodendrocytes depend on expression of connexin43 protein in astrocytes. J. Neurosci. 33, 7985-7996. doi: 10.1523/ JNEUROSCI.5874- 12.2013

Mei, X., Ezan, P., Giaume, C., and Koulakoff, A. (2010). Astroglial connexin immunoreactivity is specifically altered at $\beta$-amyloid plaques in $\beta$-amyloid precursor protein/presenilin1 mice. Neuroscience 171, 92-105. doi: 10.1016/j. neuroscience.2010.08.001

Modi, K. K., Roy, A., Brahmachari, S., Rangasamy, S. B., and Pahan, K. (2015). Cinnamon and its metabolite sodium benzoate attenuate the activation of p21rac and protect memory and learning in an animal model of Alzheimer's disease. PLoS One 10:e0130398. doi: 10.1371/journal.pone.0130398

Nagy, J. I., Ionescu, A. V., Lynn, B. D., and Rash, J. E. (2003). Connexin29 and connexin32 at oligodendrocyte and astrocyte gap junctions and in myelin of the mouse central nervous system. J. Comp. Neurol. 464, 356-370. doi: 10.1002/ cne.10797

Nagy, J. I., Li, W., Hertzberg, E. L., and Marotta, C. A. (1996). Elevated connexin43 immunoreactivity at sites of amyloid plaques in Alzheimer's disease. Brain Res. 717, 173-178. doi: 10.1016/0006-8993(95)01526-4

Nathan, C., Calingasan, N., Nezezon, J., Ding, A., Lucia, M. S., La Perle, K., et al. (2005). Protection from Alzheimer's-like disease in the mouse by genetic ablation of inducible nitric oxide synthase. J. Exp. Med. 202, 1163-1116. doi: 10.1084/jem.20051529

Navarro, V., Sanchez-Mejias, E., Jimenez, S., Muñoz-Castro, C., Sanchez-Varo, R., Davila, J. C., et al. (2018). Microglia in Alzheimer's disease: activated, dysfunctional or degenerative. Front. Aging Neurosci. 10:140. doi: 10.3389/fnagi. 2018.00140

Oakley, H., Cole, S. L., Logan, S., Maus, E., Shao, P., Craft, J., et al. (2006). Intraneuronal beta-amyloid aggregates, neurodegeneration, and neuron loss in transgenic mice with five familial Alzheimer's disease mutations: potential factors in amyloid plaque formation. J. Neurosci. 26, 10129-10140. doi: 10.1523/ JNEUROSCI.1202-06.2006

Oddo, S., Caccamo, A., Shepherd, J. D., Murphy, M. P., Golde, T. E., Kayed, R., et al. (2003). Triple-transgenic model of Alzheimer's Disease with plaques and tangles: intracellular A $\beta$ and synaptic dysfunction. Neuron 39, 409-421. doi: 10.1016/S0896-6273(03)00434-3

Odermatt, B., Wellershaus, K., Wallraff, A., Seifert, G., Degen, J., Euwens, C., et al. (2003). Connexin 47 (Cx47)-Deficient Mice with Enhanced Green Fluorescent Protein Reporter Gene Reveal Predominant Oligodendrocytic Expression of Cx47 and Display Vacuolized Myelin in the CNS. J. Neurosci. 23, 4549-4559. doi: 10.1523/jneurosci.23-11-04549.2003

Ohno, M., Chang, L., Tseng, W., Oakley, H., Citron, M., Klein, W. L., et al. (2006). Temporal memory deficits in Alzheimer's mouse models: rescue by genetic deletion of BACE1. Eur. J. Neurosci. 23, 251-260. doi: 10.1111/j.1460-9568. 2005.04551.x

Orellana, J. A., Froger, N., Ezan, P., Jiang, J. X., Bennett, M. V. L., Naus, C. C., et al. (2011a). ATP and glutamate released via astroglial connexin 43 hemichannels mediate neuronal death through activation of pannexin 1 hemichannels. J. Neurochem. 118, 826-840. doi: 10.1111/j.1471-4159.2011.07210.x

Orellana, J. A., Sáez, P. J., Shoji, K. F., Schalper, K. A., Palacios-Prado, N., Velarde, V., et al. (2009). Modulation of brain hemichannels and gap junction channels by pro-inflammatory agents and their possible role in neurodegeneration. Antioxid. Redox Signal. 11, 369-399. doi: 10.1089/ars.2008.2130

Orellana, J. A., Shoji, K. F., Abudara, V., Ezan, P., Amigou, E., Saez, P. J., et al. (2011b). Amyloid -induced death in neurons involves glial and neuronal hemichannels. J. Neurosci. 31, 4962-4977. doi: 10.1523/JNEUROSCI.6417-10. 2011

Orthmann-Murphy, J. L., Freidin, M., Fischer, E., Scherer, S. S., and Abrams, C. K. (2007). Two distinct heterotypic channels mediate gap junction coupling between astrocyte and oligodendrocyte connexins. J. Neurosci. 27, 1394913957. doi: 10.1523/JNEUROSCI.3395-07.2007

Papaneophytou, C., Georgiou, E., and Kleopa, K. A. (2019). The role of oligodendrocyte gap junctions in neuroinflammation. Channels 13, 247-263. doi: 10.1080/19336950.2019.1631107

Parihar, M. S., and Brewer, G. J. (2010). Amyloid- $\beta$ as a modulator of synaptic plasticity. J. Alzheimers Dis. 22, 741-763. doi: 10.3233/JAD-2010-101020

Paznekas, W. A., Boyadjiev, S. A., Shapiro, R. E., Daniels, O., Wollnik, B., Keegan, C. E., et al. (2003). Connexin 43 (GJA1) mutations cause the pleiotropic phenotype of oculodentodigital dysplasia. Am. J. Hum. Genet. 72, 408-418. doi: $10.1086 / 346090$

Pelegrin, P., and Surprenant, A. (2006). Pannexin-1 mediates large pore formation and interleukin- $1 \beta$ release by the ATP-gated $\mathrm{P} 2 \mathrm{X} 7$ receptor. EMBO J. 25, 5071-5582. doi: 10.1038/sj.emboj.7601378

Pelegrin, P., and Surprenant, A. (2009). The P2X7 receptor - Pannexin connection to dye uptake and IL-1 $\beta$ release. Purinergic Signal. 5, 129-137. doi: 10.1007/ s11302-009-9141-7

Perez-Nievas, B. G., and Serrano-Pozo, A. (2018). Deciphering the astrocyte reaction in Alzheimer's disease. Front. Aging Neurosci. 10:114. doi: 10.3389/ fnagi.2018.00114

Radde, R., Bolmont, T., Kaeser, S. A., Coomaraswamy, J., Lindau, D., Stoltze, L., et al. (2006). A $\beta 42$-driven cerebral amyloidosis in transgenic mice reveals early and robust pathology. EMBO Rep. 7, 940-946. doi: 10.1038/sj.embor.7400784

Reiss, A. B., Arain, H. A., Stecker, M. M., Siegart, N. M., and Kasselman, L. J. (2018). Amyloid toxicity in Alzheimer's disease. Rev. Neurosci. 29, 613-627. doi: 10.1515/revneuro-2017-0063

Retamal, M. A., Froger, N., Palacios-Prado, N., Ezan, P., Saez, P. J., Saez, J. C., et al. (2007). Cx43 hemichannels and gap junction channels in astrocytes are regulated oppositely by proinflammatory cytokines released from activated microglia. J. Neurosci. 27, 13781-13792. doi: 10.1523/JNEUROSCI.2042-07. 2007

Roher, A. E., Weiss, N., Kokjohn, T. A., Kuo, Y. M., Kalback, W., Anthony, J., et al. (2002). Increased $A \beta$ peptides and reduced cholesterol and myelin proteins characterize white matter degeneration in Alzheimer's disease. Biochemistry 41, 11080-11090. doi: 10.1021/bi026173d

Roscoe, W. A., Kidder, G. M., and Karlik, S. J. (2007a). Experimental allergic encephalomyelitis in connexin 43-heterozygous mice. Cell Commun. Adhes. 14, 57-73. doi: 10.1080/15419060701459569

Roscoe, W. A., Messersmith, E., Meyer-Franke, A., Wipke, B., and Karlik, S. J. (2007b). Connexin 43 gap junction proteins are up-regulated in remyelinating spinal cord. J. Neurosci. Res. 85, 945-953. doi: 10.1002/jnr.21194

Rufer, M., Wirth, S. B., Hofer, A., Dermietzel, R., Pastor, A., Kettenmann, H., et al. (1996). Regulation of connexin-43, GFAP, and FGF-2 is not accompanied by changes in astroglial coupling in MPTP-lesioned, FGF-2-treated parkinsonian mice. J. Neurosci. Res. 46, 606-617. doi: 10.1002/(sici)1097-4547(19961201)46: $5<606$ ::aid-jnr9>3.0.co;2-n

Sargiannidou, I., Vavlitou, N., Markoullis, K., Kyriacou, K., Scherer, S. S., and Kleopa, K. A. (2009). Axonal degeneration in mouse models of CMT1X neuropathy. Glia 57:s118.

Scemes, E., and Giaume, C. (2006). Astrocyte calcium waves: What they are and what they do. Glia 54, 716-725. doi: 10.1002/glia.20374 
Sjöbeck, M., Haglund, M., and Englund, E. (2005). Decreasing myelin density reflected increasing white matter pathology in azheimer's disease - A neuropathological study. Int. J. Geriatr. Psychiatry 20, 919-926. doi: 10.1002/ gps. 1384

Skaper, S. D. (2012). Alzheimer's disease and amyloid: Culprit or coincidence? Int. Rev. Neurobiol. 102, 277-316. doi: 10.1016/B978-0-12-386986-9.00011-9

Smith, P. K., Krohn, R. I., Hermanson, G. T., Mallia, A. K., Gartner, F. H., Provenzano, M. D., et al. (1985). Measurement of protein using bicinchoninic acid. Anal. Biochem. 150, 76-85. doi: 10.1016/0003-2697(85)90442-7

Sturchler-Pierrat, C., Abramowski, D., Duke, M., Wiederhold, K. H., Mistl, C., Rothacher, S., et al. (1997). Two amyloid precursor protein transgenic mouse models with Alzheimer disease-like pathology. Proc. Natl. Acad. Sci. U.S.A. 94, 13287-13292. doi: 10.1073/pnas.94.24.13287

Sutor, B., Schmolke, C., Teubner, B., Schirmer, C., and Willecke, K. (2000). Myelination defects and neuronal hyperexcitability in the neocortex of Connexin 32-deficient mice. Cereb. Cortex 23, 4549-4559. doi: 10.1093/cercor/ 10.7.684

Takeuchi, H., and Suzumura, A. (2014). Gap junctions and hemichannels composed of connexins: potential therapeutic targets for neurodegenerative diseases. Front. Cell. Neurosci. 8:189. doi: 10.3389/fncel.2014.00189

Talantova, M., Sanz-Blasco, S., Zhang, X., Xia, P., Akhtar, M. W., Okamoto, S. I., et al. (2013). A $\beta$ induces astrocytic glutamate release, extrasynaptic NMDA receptor activation, and synaptic loss. Proc. Natl. Acad. Sci. U.S.A. 110, E2518E2527. doi: 10.1073/pnas.1306832110

Tress, O., Maglione, M., May, D., Pivneva, T., Richter, N., Seyfarth, J., et al. (2012). Panglial gap junctional communication is essential for maintenance of myelin in the CNS. J. Neurosci. 32, 7499-7518. doi: 10.1523/JNEUROSCI.0392-12. 2012

Uhlenberg, B., Schuelke, M., Rüschendorf, F., Ruf, N., Kaindl, A. M., Henneke, M., et al. (2004). Mutations in the gene encoding gap junction protein $\alpha 12$ (Connexin 46.6) cause Pelizaeus-Merbacher-like disease. Am. J. Hum. Genet. 75, 251-260. doi: 10.1086/422763

Watanabe, M., Masaki, K., Yamasaki, R., Kawanokuchi, J., Takeuchi, H., Matsushita, T., et al. (2016). Th1 cells downregulate connexin 43 gap junctions in astrocytes via microglial activation. Sci. Rep. 6:38387. doi: 10.1038/srep38387

Wu, C. Y., Hsieh, H. L., Jou, M. J., and Yang, C. M. (2004). Involvement of p42/p44 MAPK, p38 MAPK, JNK and nuclear factor-kappa B in interleukin- $1 \beta$-induced matrix metalloproteinase-9 expression in rat brain astrocytes. J. Neurochem. 90, 1477-1488. doi: 10.1111/j.1471-4159.2004.02682.x
Wu, D., Tang, X., Gu, L. H., Li, X. L., Qi, X. Y., Bai, F., et al. (2018). LINGO-1 antibody ameliorates myelin impairment and spatial memory deficits in the early stage of 5XFAD mice. CNS Neurosci. Ther. 24, 381-393. doi: 10.1111/cns. 12809

Xiao, N. A., Zhang, J., Zhou, M., Wei, Z., Wu, X. L., Dai, X. M., et al. (2015). Reduction of glucose metabolism in olfactory bulb is an earlier Alzheimer's disease-related biomarker in 5XFAD mice. Chin. Med. J. 128, 2220-2227. doi: 10.4103/0366-6999.162507

Xing, L. Y., Yang, T., Cui, S., Sen, and Chen, G. (2019). Connexin hemichannels in astrocytes: role in CNS disorders. Front. Mol. Neurosci. 12:23. doi: 10.3389/ fnmol.2019.00023

Xu, C. Y., Zhang, W. S., Zhang, H., Cao, Y., and Zhou, H. Y. (2019). The Role of Connexin-43 in the inflammatory process: a new potential therapy to influence Keratitis. J. Ophthalmol. 2019:9312827. doi: 10.1155/2019/9312827

Yamasaki, R. (2018). Connexins in health and disease. Clin. Exp. Neuroimmunol. 9, 30-36. doi: 10.1111/cen3.12433

Yan, J., Thomson, J. K., Zhao, W., Wu, X., Gao, X., DeMarco, D., et al. (2018). The stress kinase JNK regulates gap junction $\mathrm{Cx} 43$ gene expression and promotes atrial fibrillation in the aged heart. J. Mol. Cell. Cardiol. 114, 105-115. doi: 10.1016/j.yjmcc.2017.11.006

Yi, C., Mei, X., Ezan, P., Mato, S., Matias, I., Giaume, C., et al. (2016). Astroglial connexin43 contributes to neuronal suffering in a mouse model of Alzheimer's disease. Cell Death Differ. 23, 1691-1701. doi: 10.1038/cdd.20 16.63

Yool, D. A., Edgar, J. M., Montague, P., and Malcolm, S. (2000). The proteolipid protein gene and myelin disorders in man and animal models. Hum. Mol. Genet. 76, 813-825. doi: 10.1093/hmg/9.6.987

Conflict of Interest: The authors declare that the research was conducted in the absence of any commercial or financial relationships that could be construed as a potential conflict of interest.

Copyright (c) 2020 Angeli, Kousiappa, Stavrou, Sargiannidou, Georgiou, Papacostas and Kleopa. This is an open-access article distributed under the terms of the Creative Commons Attribution License (CC BY). The use, distribution or reproduction in other forums is permitted, provided the original author(s) and the copyright owner(s) are credited and that the original publication in this journal is cited, in accordance with accepted academic practice. No use, distribution or reproduction is permitted which does not comply with these terms. 